\title{
Interlaminar Shear Characterization of Ultra-High Molecular Weight Polyethylene (UHMWPE) Composite Laminates
}

Travis A. Bogetti ${ }^{a *}$, Matthew Walter ${ }^{b}$, Jeffrey Staniszewski ${ }^{c}$, Julia Cline ${ }^{a}$

\begin{abstract}
Ultra-high molecular weight polyethylene (UHMWPE) fiber-reinforced composites have received widespread attention in the literature due to their attractive ballistic protection attributes. Recently, investigators are recognizing and demonstrating the significant role that interlaminar shear has on their ballistic performance. In this paper, we present a characterization methodology to quantify the quasi-static interlaminar shear strength and nonlinear interlaminar shear stress-strain response of UHMWPE composite laminates. The methodology uses a tension loaded double-lap coupon design to introduce interlaminar shear loading. Coupon displacement measurements using Digital Image Correlation (DIC) coupled with Finite Element Analysis (FEA) incorporating nonlinear material behavior and traction-separation behavior is an integral part of the data reduction scheme. This research provides a unique methodology for developing interlaminar shear constitutive models for UHMWPE composite laminates, which are critically needed to improve the accuracy of ballistic impact simulations for the development of more efficient armor designs.
\end{abstract}

Keywords: Ultra-high molecular weight polyethylene composite $(A)$, interlaminar shear characterization $(B)$, finite element analysis $(C)$, traction-separation behavior $(C)$ Introduction 


\section{Motivation and Background}

For decades, fiber-reinforced UHMWPE composites have received a great deal of attention in the literature because of the excellent ballistic performance they exhibit in a wide array of personnel and vehicle armor applications. These "soft composites" are unique from traditional structural composites in that they are comprised of unidirectionally oriented UHMWPE fibers, loosely aligned and poorly bonded within a rubbery, compliant matrix at very high fiber volume content (i.e., upwards of $85 \%$ ). These materials are most often used in laminate form where individual unidirectional plies (or layers) are oriented in a repeating [0/90] architecture and subsequently thermoformed into a suitable armor platform. Despite the widespread use of these materials in protective systems, their response and failure in the ballistic environment is still not well understood. There are a number of factors that contribute to this knowledge gap. First, these materials exhibit very complex deformation and failure mechanisms which result from the multiscale hierarchy of the microstructure (i.e., fiber/matrix, ply, laminate) responding to a broad spectrum of loading rates during impact. Second, in composite laminate form these materials are highly anisotropic (i.e., high modulus fibers in a compliant matrix) and the inherent nonlinear, viscoelastic, rate dependent behavior of the fiber/matrix constituents combined with poor fiber/matrix bonding makes property characterization extremely difficult. Not surprisingly, most ASTM experimental methods are not directly applicable to UHMWPE composites, and thus the availability of characterization data for these materials is quite limited in the literature. Despite the challenges associated with the accurate characterization of these materials, a good number of investigators have made advances in testing these unique materials. Simple uniaxial tensile tests of [0/90] and [+45/-45] UHMWPE laminates have been successfully performed, but difficulties associated with gripping the material have led to the development of specialized fixtures and specimen configurations to apply the axial loading [1-6]. Success has also been reported on the characterization of UHMWPE composite compression behavior [6-8] as well as Mode I and II fracture toughness $[4,9]$. 
While there are many factors that influence the ballistic performance and complex impactinduced failure mechanisms in UHMWPE composites [10-12], the ballistic efficiency of these materials has been largely attributable to the fiber properties (i.e., low density, high tensile modulus, strength and tenacity) [13-14]. For example, the Cunniff scaling velocity [13] has been useful in providing the design rationale for UHMWPE and other high performance fiber systems in many ballistic armor applications. In recent years, however, the significant role that the matrix properties play on ballistic performance has become the subject of intense study in the research community [1,3,4,7-9,15-19]. A number of researchers have performed systematic studies on UHMWPE laminates and have clearly demonstrated the significant influence the matrix properties have on impact and ballistic performance. For example, Karthikeyan et al. [15] found that lower matrix shear strength corresponded to both the highest ballistic limit and the highest mid-span plate deflection in their study to quantify the effect of shear strength on the deformation and penetration response of UHMWPE composite plates. Their work underlines an important conclusion; that the Cunniff scaling velocity does not fully capture the ballistic trends of certain fiber reinforced materials, since it does not explicitly take into account the effects of the matrix properties. This relationship between low matrix shear strength and improved ballistic performance was also demonstrated in Karthikeyan et al. [3]. The significant role that the matrix plays on ballistics is further supported by the fact that delamination, which is a matrix dominated failure mechanism often observed in UHMWPE composite laminates, has been shown by a number of investigators to be an influential factor governing ballistic response and performance $[1,9,11,18]$.

With the emerging consensus that the matrix plays a key role in ballistic performance, investigators have sought various methods to accurately characterize the matrix dominated response of UHMWPE composites, with a particular focus on the interlaminar shear behavior in laminates [3,8,9,16]. Karthikeyan et al. [3] and Liu et al. [16] used a tension loaded double-notch type sample to characterize interlaminar shear strength and shear stress versus shear displacement behavior across the loaded shear interface. Chocron et al. [8] performed similar tests using a compression loaded version of the double-notched configuration. These investigators did 
not report an actual shear stress versus shear strain relationship due to difficulties associated with calculating the shear strains across the shear loaded interface. More recently however, Meshi et al. [9] developed both a single lap joint and a double-end-notch specimen design to characterize the interlaminar shear behavior. Using DIC measurements, they were successful in characterizing the nonlinear interlaminar shear stress-strain response in UHMWPE composite laminates. While their research seems to provide a straightforward and reasonable estimate for the interlaminar shear stress-strain response, the accuracy of the DIC strain calculations across the nonuniformly loaded lap shear interface was not easily quantified.

In this work, we propose a unique methodology for characterizing the nonlinear interlaminar shear stress-strain response of UHMWPE composite laminates. The approach uses a tension loaded double-lap coupon design to introduce interlaminar shear loading between ply interfaces and circumvents accuracy issues associated with measuring nonuniform strains in close proximity to the lap shear interface. The nonlinear interlaminar stress-strain response is obtained through a data reduction scheme that uses displacement fields obtained from digital image correlation (DIC) along with a finite element analysis (FEA) incorporating nonlinear material behavior and tractionseparation behavior. The methodology presented here offers an alternative approach for characterizing the interlaminar shear constitutive response and failure of UHMWPE composite laminates, providing data which is critically needed to improve the accuracy of ballistic impact simulations for the development of more efficient armor designs.

\section{Design and processing of double-lap shear coupons}

\section{$\underline{\text { Composite architecture }}$}

The trade name of the UHMWPE composite material used in this work is Spectra Shield II SR-3136 [20]. It is commercially available in laminated sheet form and is usually supplied on a roll $1.6 \mathrm{~m}$ wide by $150.0 \mathrm{~m}$ long. At the unidirectional ply level, highly aligned polyethylene fibers are embedded in a polyurethane matrix. The fiber content of this composite is approximately $85 \%$ by volume. The material has a density of $0.97 \mathrm{~g} / \mathrm{cm}^{3}$ and a melt temperature of approximately $147^{\circ} \mathrm{C}$. 
The laminated sheet, as it comes off the roll, is comprised of four individual plies of pre-consolidated unidirectional material aligned in a [0/90/0/90] architectural configuration. This sheet is approximately $0.26 \mathrm{~mm}$ thick with an average per ply thickness one fourth the total sheet thickness, or $0.065 \mathrm{~mm}$. All material characterization presented in this effort is performed on coupons cut from laminates that were 40 sheets thick, with an average total laminate thickness of $10.40 \mathrm{~mm}$. As depicted in Figure 1, the composite laminate architecture of all coupons tested in this study is essentially a 160 ply cross-ply construction or $[0 / 90]_{80}$.

\section{Double-lap coupon design and assembly}

In studying the interlaminar shear behavior of this material with a double-lap coupon, it is extremely important to isolate the matrix dominated behavior from any fiber loading. This is particularly necessary for this highly anisotropic material, where the longitudinal stiffness of the fiber is several orders of magnitude greater than that of the matrix. Any fiber bridging across the lap joint will directly load fibers in tension and dominate the measured response. Other investigators have used a double-notched shear coupon to study the interlaminar shear response of UHMWPE composites $[3,8,16]$, where shear planes were created by strategically notching the sample surface and drilling a hole in the coupon after it was processed. As explained in their work, extreme care was taken to align the notches and hole to eliminate the possibility of fiber bridging. An alternate approach, similar to that adopted by Meshi et al. [9], is taken in our effort to avoid issues associated with fiber bridging. A double-lap shear coupon is designed where the lap shear planes are manufactured into the sample and no post machining of notches or holes is required. This coupon design completely eliminates the possibility of fiber bridging, thus ensuring a pure, matrix dominated interlaminar shear response. The lap shear planes are created with strategic placement of a fluoropolymer release film and are assembled with the unprocessed sheets of material into a panel. The lap shear plane for this coupon design is $2.54 \mathrm{~cm}$ long. An illustration of this assembly design is shown in Figure 2, where sectional views clearly illustrate the concept and other relevant dimensions. 
The panel is processed between a pair of heated platens while temperature and pressure are simultaneously applied. Laminates are hot pressed at $132^{\circ} \mathrm{C}$ under a pressure of $13.8 \mathrm{MPa}$. Standard peel ply release film is used between the top and bottom of the composite panel assembly and the heated platens to allow for easy separation after processing. The individual test coupons are subsequently water jet machined from this panel. It is important to locally melt, or "spot weld", the laminated sheets together in the panel assembly using a soldering gun to prevent shifting of the individual sheets during handling prior to processing (see Figure 3). The soldering gun is operated at a temperature of $260^{\circ} \mathrm{C}$ and the tip of the gun is pushed completely through all 40 sheets of the assembly to secure them in place.

The lap shear planes are processed in-place to allow for precise control of the loaded interface and ensure that no fibers are bridged across the loaded shear plane. The thickness of the release film used to create the lap shear planes is insignificant when compared to that of the unprocessed sheet material; consequently, these films had no influence on the ply interface architecture of the processed laminate. As mentioned previously, all laminates in this study are of a $[0 / 90]$ construction and the centrally located lap shear interface used in all coupons is that which exists between a [0] ply and a [90] ply, as illustrated in Figure 4. Note that within the shear loaded region there are "manufactured" interfaces, those that are created during assembly of the preconsolidated laminated sheets, and "as-received" interfaces, those that already exist in the raw sheet material. Deformation measurements made within the shear loaded region were not of sufficient resolution to distinguish any differences in the behavior of these two types of interfaces.

\section{$\underline{\text { Panel processing }}$}

An in-house hot press configuration has been devised to provide precise control of platen alignment, temperature and pressure to ensure a high degree of uniformity and quality control for panel processing and coupon manufacture. The set-up includes a pair of independently operated resistance heated platens that are placed in a custom built Instron-Satec 4-post compression load frame with a $4448 \mathrm{kN}$ capacity. The platens dimensions are $20.32 \mathrm{~cm}$ by $20.32 \mathrm{~cm}$ by $7.62 \mathrm{~cm}$ 
thick, equivalent to the in-plane dimensions of the UHMWPE panels. Each heated platen is manufactured from A-36 steel and contains four $1200 \mathrm{~W}$ heating elements along with integrated water cooling channels and J-type thermocouples to monitor temperature. The load frame is equipped with self-aligning platens and each of the heated platens' surfaces are machined flat to tight tolerances to help ensure uniform pressure distribution on the processed UHMWPE composite panels. The resistance heated platens are shown in Figure 5 with a UHMWPE panel positioned between them. A more detailed description of the hot press configuration is shown in Figure 6 . The heated platens are sandwiched between two titanium plates with a lower thermal conductivity to help maintain thermal stability during the process cycle. A thick aluminum surround frame is used to prevent the UHMWPE material from squeezing or flowing out from between the platens during processing. (Note that the Titanium plates and the surround frame with blocks are not illustrated in Figure 5.) The temperature and pressure cycles shown in Figure 7 are used to process all the UHMWPE laminates in this study. A thermocouple is embedded in the center of the each laminate and monitored to verify that the laminate temperature profile closely followed the thermal cycle shown in Figure 7.

\section{Experimental procedures}

\section{$\underline{\text { Coupon machining and DIC preparation }}$}

After processing, individual coupons are water jet machined from the UHMWPE laminates according to the template shown in Figure 2. Overall coupon dimensions are $20.32 \pm 0.11 \mathrm{~cm}$ long by $1.90 \pm 0.06 \mathrm{~cm}$ wide by approximately $1.07 \pm 0.03 \mathrm{~cm}$ thick. Coupon thicknesses are found to be essentially constant with minor variations being held to less than a few percent due to the rigid constraints of the hot press configuration used to consolidate the laminates. DIC prep involves spraying a white background for contrast followed by black speckling in the vicinity of double-lap shear region. This allows displacement measurements to be recorded under load until catastrophic failure of the interface. 


\section{Testing}

The machined double-lap shear coupons are tested in tension on an Instron 5985 load frame with Bluehill III software using a $30 \mathrm{kN}$ load cell. The coupons are secured at both ends in wedge action 10kN Screw Grips to a depth of $38 \mathrm{~mm}$ and 180-grit sandpaper is used to mitigate slipping. The tensile loading was performed under a displacement controlled rate of $1.3 \mathrm{~mm} / \mathrm{min}$ and the machine load and displacement field histories are recorded. The data documented in this report is for a total of five coupons, all machined from a single panel. Additional coupons were tested from a series of panels, using the same process cycle, preparation, and test procedure, and demonstrate good repeatability of the methodology. The coupon-to-coupon variability in the data presented in this report is representative of that which was observed for other panels tested.

\section{Finite element analysis of the double-lap coupon design}

\section{$\underline{\text { Coupon Model }}$}

The tension loaded double-lap shear coupon is modeled in ABAQUS [22] using an implicit analysis with 4-node, fully integrated, 2D bilinear, plane strain quadrilateral elements (type CPE4). Since the double-lap shear coupon is symmetric about the loading direction (x-direction), only half of the coupon is modeled with symmetry applied along the centerline (see Figure 9). The grips are not explicitly modeled, but the boundary conditions are enforced as to account for the traction 
loading of the grips at the coupon surfaces, neglecting the through thickness compression load components. Tension in the coupon is introduced by fixing displacements on the coupon surface at one end $(\mathrm{x}=0)$, where the coupon is in contact with the stationary grips, and displacement controlled loading is enforced on the opposite end, where the coupon is in contact with the translating grips. The finite element model contains a total of 3213 nodes and 3020 elements. Numerical convergence is confirmed for the mesh shown, with 20 elements through the half coupon thickness being sufficient. Additionally, the mesh is biased to have more refinement near the lap shear interface and less refinement near the grips, since they are remote from the area of interest. A summary of the coupon model and associated boundary conditions is presented in Figure 9.

\section{$\underline{\text { UHMWPE laminate material properties }}$}

The UHMWPE composite material used in this study is Spectra Shield II SR-3136 with a ply architecture of a $[0 / 90]_{s}$ cross-ply laminate. We model this laminate as a homogeneous continuum with a three-dimensional set of theoretically-based properties derived from the fiber-matrix level. First, the individual ply or [0] lamina properties of the composite are estimated from a continuous fiber micromechanical model [23] using typical Spectra fiber and polyurethane matrix properties found in the literature $[24,25]$. The fiber properties are presented in Table 1. The fiber properties are assumed to be transversely isotropic $\left(e . g ., E_{2}^{f}=E_{3}^{f}, G_{12}^{f}=G_{13}^{f}, v_{12}^{f}=v_{13}^{f}\right)$ and the properties of the matrix are $E^{m}=5.00 \mathrm{GPa}$ and $v^{m}=0.3$. Using the reported fiber volume fraction for this material $\left(v_{f}=85 \%\right)$, the transversely isotropic properties of a single ply or [0] lamina are estimated. These [0] lamina properties are then input into a three-dimensional laminate analysis to estimate the linear-elastic effective properties for the $[0 / 90]_{s}$ laminate architecture. The laminate analysis code LAM3D [26], developed by the U.S. Army Research Laboratory, was used to compute a threedimensional set of effective properties for the laminate. The LAM3D code is based on the theoretical work of Chou et al. [27] and predicts three-dimensional thermo-mechanical properties of thick laminated composite media. A summary of the estimated lamina and laminate properties are given in Table 1. 
Nonlinear material finite element analysis

The laminate properties in Table 1 constitute a theoretically derived set of threedimensional, anisotropic, linear elastic engineering constants for use in the coupon model. Since we know that the material exhibits significant material nonlinearity in the interlaminar shear direction, we replace the linear shear constants $G_{x z}=G_{y z}$, in Table 1, with nonlinear strain dependent constitutive functions, $\left(\right.$ e.g.,$\left.G_{x z}\left(\gamma_{x z}\right)=G_{y z}\left(\gamma_{y z}\right)\right)$ so that we can more realistically simulate the interlaminar shear stress-strain response of the laminate under load. ABAQUS can only accommodate anisotropic material nonlinearity through a user defined (UMAT) material constitutive model. Consequently, we use the UMAT material model LAMPATNL [28] to incorporate the nonlinear material behavior into the interlaminar shear directions. LAMPATNL is a UMAT material model for ABAQUS that, like LAM3D, was developed by the ARL and is based on the theoretical laminated media analysis of Chou et al. [27]. LAMPATNL uses nonlinear stress-strain constitutive relations as input and allows us to model the effective nonlinear laminate response of

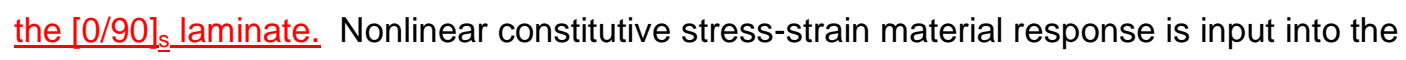
LAMPATNL material model using the three parameter Ramberg-Osgood equation [29]

$$
\tau_{x z}\left(\gamma_{x z}\right)=\frac{G_{o} \gamma_{x z}}{\left(1+\left\{\frac{G_{o} \gamma_{x z}}{\tau_{o}}\right\}^{n}\right)^{\frac{1}{n}}}
$$

where $\tau_{x z}\left(\gamma_{x z}\right)$ is the strain dependent shear stress, $\gamma_{x z}$ is the shear strain, $G_{o}$ is the initial linear slope of the stress-strain response, $\tau_{o}$ is the asymptotic stress level, and $n$ is a shape parameter, graphically shown in Figure 10. We use this nonlinear constitutive relation in the FEA to back calculate the actual interlaminar shear stress-strain response of the UHMWPE composite laminate by correlating model displacement predictions with DIC measured displacements from coupon tests. The back calculations are performed through a series of finite element simulations where the Ramberg-Osgood parameters are systematically varied until model predictions match the experimentally measured coupon displacement fields. In this manner specific values of $G_{o}, \tau_{o}$, and 
$n$ are determined that provide a close fit to the actual interlaminar shear stress-strain response of the Spectra Shield II SR-3136 composite laminate material.

Sensitivity studies were performed with the finite element coupon model to quantify the effects of the other laminate properties listed in Table 1 on the overall coupon response. It was found that the coupon response was most significantly influenced by the interlaminar shear properties assumed in the model. All other properties were found to have a negligible effect on the predicted coupon deformations. This was not surprising considering the anisotropy of the material properties and the nature of the loading conditions. These findings validate the back calculation approach used in this study for characterizing the interlaminar shear behavior of the UHMWPE composite laminate.

\section{$\underline{\text { Traction-separation }}$}

The nonlinear analysis outlined above predicts the loading portion of the coupon response but does not accommodate any unloading associated with interlaminar failure at the lap shear interface. The coupons in this study are loaded to complete failure and displacements are recorded for the entire loading and unloading history. Experimental observations reveal that coupon failure is localized to a single interface in the center of the lap shear plane. Failure of the lap shear interface is simulated by adding a surface based traction-separation contact condition to the existing doublelap coupon model. This condition allows the model to more realistically capture the material response by accommodating a gradual unloading of the interface $[30,31]$. The interface location in the coupon model where this condition is imposed is shown in Figure 9. Sufficient refinement of the cohesive model response was obtained using a total of 50 nodes along the surface of the interface. The traction-separation law used in this study is defined by the three parameters shown in Figure 11: the initial slope of the stress-displacement relationship before separation, $K$, the stress where unloading begins, $\tau_{s}$, and the total displacement at complete separation, $\Delta_{s}$. In our analysis, the value of $K$ is chosen to be sufficiently large as to essentially prevent separation before the unloading. Specific values of $K, \tau_{s}$, and $\Delta_{S}$ for the Spectra Shield II SR-3136 laminates are back 
calculated through model correlation with the experimentally measured DIC response from the coupons in a similar manner to how the Ramberg-Osgood parameters were determined.

\section{Results and discussion}

Definition of average stress and strain

Full field deformations on the edge of the coupon are measured across the lap region, as a function of the applied load, using the DIC technique. To help facilitate interpretation of the experimental displacement measurements, a data reduction method is chosen wherein an "average" interlaminar shear strain is defined across the lap shear interface within the coupon. This average interlaminar shear strain, $\gamma_{a v e}$, was calculated according to the simple strain relationship:

$$
\gamma_{\text {ave }}=\frac{\Delta}{t}
$$

where $\Delta$ is the shear displacement measured from the DIC and $t$ is thickness across which the average strain is assumed (see Figure 12). An average interlaminar shear stress was also assumed along the lap shear interface as:

$$
\tau_{\text {ave }}=\frac{P}{A}
$$

where $P$ is the applied tensile load and $A$ is the area of the lap shear interface. This definition of average shear stress assumes that the shear stresses along the lap shear interface are uniform. Experimental DIC displacement measurements support this assumption in that the calculated average interlaminar shear strain, $\gamma_{a v e}$, is found to be essentially constant along a significant portion of the $2.54 \mathrm{~cm}$ lap shear interface. Additional results from the nonlinear FEA are presented later that further support the uniform stress assumption.

\section{$\underline{\text { Coupon response under load }}$}

By continuously recording the load and displacement across the lap shear interface of the coupon during the test, the average interlaminar shear stress-strain response of the UHMWPE composites is obtained using Equations (2) and (3). It is desirable to compute strains as close to the lap shear interface as possible, since this is where the average shear stress assumption is most 
valid. Resolution of the DIC cameras, however, limits our ability to record data within $0.52 \mathrm{~mm}$ of either side of the interface. Consequently, the smallest dimension across the interface that we could compute strains is $1.04 \mathrm{~mm}$ or $10 \%$ of the total coupon thickness $10.40 \mathrm{~mm}$. Therefore, average interlaminar shear strains are computed at a distance corresponding to $10 \%$ of the total coupon thickness as a function of the applied tensile load. Average shear strains are also computed at distances corresponding to of $20 \%$ and $30 \%$ of the total coupon thickness. These average strains provide a convenient way to directly compare the experimental data to the finite element model predictions. They also provide valuable insight into the unique interlaminar shear deformation mechanics of the material.

The average interlaminar shear stress versus average shear strain curves based on Equations (2) and (3) and DIC measurements taken across $10 \%, 20 \%$, and $30 \%$ of the total coupon thickness are shown in Figure 13. The interlaminar strength of this material, corresponding to this set of curves, is $\tau_{u l t}=2038.0 \pm 82.0 \mathrm{kPa}(P=1528.5 \pm 61.5 \mathrm{~N})$. The curves exhibit significant nonlinearity and there is considerable energy associated with the pre- and post-failure loading of the interface. When comparing the curves, it is evident that the average response stiffens as the distance over which the strains are computed increase (i.e., the $30 \%$ curve is stiffer than the $10 \%$ curve) due to the fact that the shear displacements and shear stresses are non-uniform, being larger nearer to the interface. Essentially, the strains computed further from the interface are including smaller displacements into the average strain and thus yield a stiffer average stress-strain profile.

$\underline{\text { Interlaminar shear stress-strain constitutive model }}$

The average strains for all of the stress-strain curves are computed over multiple laminated sheets of material and include many alternating plies of [0] and [90] architecture. The lap shear interface in each case is between a [0] and [90] ply (see Figure 4). Our goal in this effort is to determine an average or homogeneous interlaminar shear constitutive model for the Spectra Shield II SR-3136 composite laminate material. As discussed previously, the nonlinear FEA is used to 
back calculate the actual interlaminar shear stress-strain response of the UHMWPE composite laminate, (e.g., $G_{x z}\left(\gamma_{x z}\right)$ ), by correlating model displacement predictions with DIC measured displacements from the coupon tests. Specifically, the finite element model predictions for the average interlaminar shear stress-strain response are correlated to the experimentally measured average shear stress-strain response as measured across $10 \%$ of the total coupon thickness. After running a series of FEA iterations, the specific back calculated Ramberg-Osgood parameters needed to match the data at $10 \%$ of the total coupon thickness are found to be $G_{o}=55.2 \mathrm{MPa}$, $\tau_{o}=1.65 \mathrm{MPa}$, and $n=0.95$. The correlation at $10 \%$ is shown in Figure 14 along with the associated interlaminar shear stress-strain constitutive model used in the FEA (labeled FEA input), which is also considered to be the actual constitutive model for the UHMWPE laminate composite. Validation of this constitutive model is then performed by comparing model predictions with the experimentally measured average shear stress-strain responses as measured across $20 \%$ and $30 \%$ of the total coupon thickness. As shown in Figure 15, reasonably good agreement was achieved for the $20 \%$ and $30 \%$ curves using the back calculated constitutive model determined from the $10 \%$ curve. A slight over prediction of the average stress-strain response is noted, but is not unreasonable given the sample to sample variability inherent in the data. In developing this nonlinear constitutive model, only agreement for the loading portion of the curves is relevant, since the traction-separation behavior which allows for unloading has yet to be included in the model. It is noted here that although a direct comparison cannot be made to the stress-strain data reported by Meshi et al. [9], since a different material system was used, the results are quite similar when compared both quantitatively and qualitatively.

At this point we revisit the uniform shear stress assumption along the interface. Here we use the FEA to examine the predicted shear stress distributions within the coupon to gain insight into the unique behavior of this material under interlaminar shear loading. A comparison is made between linear and nonlinear material model predictions for the interlaminar shear stress development along the lap shear interface. (Both models use the linear laminate properties listed in Table 1. The nonlinear analysis replaces $G_{x z}$ with $G_{x z}\left(\gamma_{x z}\right)$, as described above.) In Figure 16, 
predicted stress profiles along the lap shear interface are presented for applied average shear stresses at $10 \%, 28 \%$, and $55 \%$ of the ultimate $\left(\tau_{u l t}=2038.0 \pm 82.0 \mathrm{kPa}\right.$ or $\left.P=1971.8 \pm 79.4 \mathrm{~N}\right)$. Not surprisingly, predicted shear stresses are significantly more uniform for the nonlinear analysis than for the linear analysis. It is expected that the nonlinear analysis provides a much more realistic representation of the actual stress distribution in the coupon. Even at the higher load levels, the shear stresses are shown to be uniform over the majority of the lap shear interface. The results presented in Figure 16 provide strong support for the uniform interlaminar shear stress assumption used in the definition of the average shear stress as given in Equation 3.

The consequences averaging nonuniform shear strains across the interface are evident from Figure 13. Here we examine these issues more closely. Steep gradients in the shear displacement and shear strain develop in close proximity to the lap interface. The nonlinear model predictions for these "average" shear displacement and strain distributions are show in Figure 17 at a load of $P=1258 \mathrm{~N}$ (or an average shear stress of $P / A=1300 \mathrm{kPa}$ ), where predicted average shear strain is plotted versus distance from the interface. The steep shear strain gradients are problematic in that they make DIC strain calculations near the interface difficult to interpret. As shown in Figure 17, significant strain variations are observed (up to say $0.25 \%$ ) within a very small dimension measuring just two ply thicknesses on either side of the shear interface. These results suggest that local ply-to-ply strain variations between the [0] and [90] layers could complicate strain calculations that attempt to homogenize or "average" displacements over this small interface dimension. A more detailed investigation into the local ply-to-ply level deformation mechanics of the material is part of our ongoing research and is reserved for future reporting.

\section{Traction-separation model}

The experimentally observed average stress-strain results reveal that a significant portion of the response is associated with the unloading of the interface. This is particularly important to characterize, as it pertains to the energy required to delaminate an interface within the laminate. As discussed in a previous section, a surfaced based traction-separation contact condition, available in 
ABAQUS, is used to model the unloading of the interface during delamination. Again, referring to Figure 11, the specific values of $K, \tau_{s}$, and $\Delta_{s}$ for the Spectra Shield II SR-3136 laminates were back calculated through model correlation with the experimentally measured DIC response from the coupons. The nonlinear constitutive model developed in the previous section was used along with the traction-separation model to match the unloading portion of the average stress-strain response. Model predictions were correlated with the experimental response measured at $10 \%$ across the interface, as shown in Figure 18. Through an iterative processes, the traction-separation law parameters needed to achieve this correlation were found to be $K=68.9 \mathrm{GPa}, \tau_{s}=1.6 \mathrm{MPa}$, and $\Delta_{s}=0.127 \mathrm{~mm}$. For validation purposes, good agreement between the model predictions and the experimentally determined average stress-strain results as measured at $20 \%$ and $30 \%$ across the interface are also shown in Figure 18.

\section{Microscopy of failed UHMWPE coupons}

The exposed surfaces of the failed lap shear coupons were studied with a three-

dimensional laser scanning confocal microscope (Keyence VK-X series) at 50x optical magnification to gain insight into the failure mechanisms associated with the shear induced interlaminar delamination. The failure surfaces of several samples were examined and observed mechanisms were consistent from sample to sample. Consequently, a representative failure surface was selected and both the optical micrograph and corresponding elevation map are presented in Figure 19. The schematic shows the microscope lens viewing direction and the path of the delamination crack running through the thickness of the [90] ply at the lap shear interface. Delamination always occurred between the [0] and [90] ply interfaces, a typical interlaminar failure. While the delamination was found to shift from one side of the [90] ply to the other, in no instances was an intralaminar failure observed, i.e., where the crack path would run along the middle of the [90] ply, with half its thickness bonding to the each of the adjacent [0] plies.

The [0] and [90] plies are shown on the micrograph of the failed surface. The corresponding elevation map helps with interpretation of the micrograph. The upper portion of the 
failure surface is clearly identified as the [0] ply and the lower portion as the [90] ply. Patches of matrix that remained adhered to the failure surface are also identified in the micrograph. Matrix material imprinted with fibers in the [90] ply that was removed can be seen in the upper portion of the micrograph. Similarly, matrix material imprinted with the [0] ply that was removed can be seen in the lower portion of the micrograph. The height scale indicated on the elevation map is consistent with the expected per ply thicknesses measured from the total laminate thicknesses.

\section{Conclusions}

In this paper, a unique method for characterizing the quasi-static nonlinear interlaminar shear stress-strain response and failure of UHMWPE composite laminates was developed using a tensile loaded double-lap shear coupon design. Lap shear planes were manufactured into the coupons (versus post drilling and machining) to eliminate potential fiber bridging and to ensure interlaminar failure at the desired ply interface. Custom heated platens were used in the coupon manufacture to enable precise control of temperature and pressure uniformity during processing. DIC measurements of full field shear displacement on the coupon edges were recorded during tensile loading to complete interface failure. The interlaminar shear response was examined using simple average stress and strain definitions. Strain calculations across the shear interface were shown to be significantly influenced by nonuniformity of the displacement field.

A finite element analysis of the double lap shear coupon was performed using anisotropic nonlinear interlaminar shear properties and traction separation behavior to describe delamination failure at the interface. The FEA was used in conjunction with the full field DIC displacement data to back calculate a specific interlaminar shear stress-strain constitutive response and failure model for Spectra Shield II SR-3136 laminates. The FEA was further used to examine the detailed stress and strain profiles within the double lap shear coupon and validate the data reduction method. Although this approach requires the use of an iterative FEA analysis, a significant advantage is that it circumvents issues associated with calculating strains in close proximity to the lap shear interface. 
While the work presented here focuses on quasi-static interlaminar shear response, ongoing and future efforts are aimed at extending this approach to higher rates of loading. With the continual advances in UHMWPE composite materials development, new methods for characterization, particularly at higher rates, are critically needed to help improve the accuracy of ballistic impact predictions to effectively design more efficient and advanced armor systems.

\section{Acknowledgments}

The authors would like to acknowledge Mr. Aristedes Yiournas and Mr. Jordan Wagner, both currently of the University of Delaware's Center for Composite Materials, for their support in processing and experimentation. This research was supported in part by an appointment to the Postgraduate Research Participation Program at the U.S. Army Research Laboratory administered by the Oak Ridge Institute for Science and Education through an interagency agreement between the U.S. Department of Energy and USARL. 


\section{References}

[1] Karthikeyen K, Russell BP. Polyethylene ballistic laminates: Failure mechanics and interface effect. Mat and Des 2014;63(1):115-125.

[2] Russell BP, Karthikeyen K, Deshpande VS, Fleck NA. The high strain rate response of ultra-high molecular weight polyethylene: from fibre to laminate. Int J Impact Eng 2013;60(1):1-9.

[3] Karthikeyan K, Russell BP, Fleck NA, O’Masta MR, Wadley HNG, Deshpande VS. The soft impact response of composite laminate beams. Int J Impact Eng 2013; 60 (1) 24-36.

[4] Lassig T, Nguyen L, May M, Riedel W, Heisserer U, van der Werff H, Hiermaier S. A non-linear orthotropic hydrocode model for ultra-high molecular weight polyethylene in impact simulations. Int J Impact Eng 2015;75(1):110-122.

[5] Levi-Sasson A, Meshi I, Mustacchi, Amarilio I, Benes D, Favorsky V, Eliasy R, Aboudi J, Haj-Ali

R. Experimental determination of linear and nonlinear mechanical properties of laminated soft composite material system. Compos Part B 2014;57:96-104.

[6] O'Masta MR, Crayton DH, Deshpande VS, Wadley HNG. Mechanisms of penetration in polyethylene reinforced cross-ply laminates. Int J Impact Eng 2015;86:249-264.

[7] Attwood JP, Khaderi SN, Karthikeyen K, Fleck NA, O’Masta MR, Wadley HNG, Deshpande VS. The out-of-plane compressive response of Dyneema® composites. J Mech Phys Solids 2014;70(1):200-226 .

[8] Chocron S, Nicholls AE, Brill A, Malka A, Namir T, Havazelet D, van der Werff H, Heisserer U, Walker JD. Modeling unidirectional composites by bundling fibers into strips with experimental determination of shear and compression properties at high pressures. Compos Sci Technol 2014;101(1):32-40.

[9] Meshi I, Amarilio I, Benes D, Haj-Ali R. Delamination behavior of UHMWPE soft layered composites. Compos Part B 2016; 98:166-175.

[10] Cheeseman BA, Bogetti TA. Ballistic impact into fabric and compliant composite laminates. Compos Struct 2003;61:161-173. 
[11] Greenhalgh ES, Bloodworth VM, lannucci L, Pope D. Fractographic observations on Dyneema® composites under ballistic impact. Compos Part A 2013;44(1):51-62.

[12] Attwood JP, Russell BP, Wadley HNG, Deshpande VS. Mechanisms of the penetration of ultrahigh molecular weight polyethylene composite beams. Int J Impact Eng 2016; 93:153-165.

[13] Cunniff PM. Dimensionless parameters for optimization of textile based body armor systems. In: Proceedings of the $18^{\text {th }}$ international symposium on ballistics. San Antonio, TX. 1999. p.1303-10. [14] Phoenix S, Porwal P. A new membrane model for the ballistic impact response and V-50 performance of multi ply fibrous systems. Int J Solids Struct 2003;40(24):6723-65.

[15] Karthikeyen K, Russell BP, Fleck NA, Wadley HNG, Deshpande VS. The effect of shear strength on the ballistic response of laminated composite plates. Eur J Mech A-Solid 2013;42(1):3553.

[16] Liu G, Thouless MD, Deshpande VS, Fleck NA. Collapse of a composite beam made from ultra high molecular-weight polyethylene fibres. J Mech Phys Solids 2014;63(1):320-335. [17] Nazarian, O, Zok, FW, Constitutive model for the shear response of Dyneema® fiber composites. Compos Part A 2014;66:73-81

[18] Nguyen LH, Ryan S, Cimpoeru SJ, Mouritz AP, Orifici AC. The effect of target thickness on the ballistic performance of ultra high molecular weight polyethylene composite. Int J Impact Eng 2015;75(1):174-183.

[19] Karthikeyan K, Kazemahvazi, S, Russell, BP, Optimal fibre architecture of soft-matrix ballistic laminates. Int J Impact Eng 2016; 88:227-237.

[20] Honeywell International, Inc., https://www.honeywell-spectra.com/product/spectra-shield-3136/, accessed September, 2016.

[21] Correlated Solutions, Inc., http://correlatedsolutions.com/, accessed September, 2016.

[22] Dassault Systemes. User documentation, ABAQUS Version 6.14, 2014.

[23] Hill R. Theory of Mechanical Properties of Fibre-Strengthened Materials: III. Self-Consistent Model. J Mech and Phys Solids, 13:189, 1965. 
[24] Honeywell International, Inc., https://www.honeywell-spectra.com/products/fibers/, accessed September, 2016.

[25] Cartwright BK, Mulcahy NL, Chhor AO, Thomas SGF, Suryanarayana M, Sandlin JD, Crouch

IG, Naebe M. Thermoforming and Structural Analysis of Combat Helmets. J Manuf Sci Eng 2015; 137(5):051011-051011-9.

[26] Bogetti TA, Hoppel CPR, Drysdale WH. Three-dimensional effective property and strength prediction of thick laminated composite media. ARL-TR-911, Army Research Laboratory, October 1995.

\section{[27] Chou PC, Carleone, J, Hsu CM. Elastic constants of layered media. J Compos Mater 1972;}

\section{6:80-93.}

[28] Staniszewski J. An improved design methodology for modeling thick-section composite structures using a multi-scale approach. University of Delaware Master's Thesis 2010. [29] Ramberg W, Osgood WR. Description of stress-strain curves by three parameters. 1943 Technical Note No. 902. National Advisory Committee for Aeronautics, Washington DC. [30] Needleman A. A continuum model for void nucleation by inclusion debonding. J App Mech 1987;54: 525-531.

[31] Park K, Paulino GH. Cohesive zone models: a critical review of traction-separation relationships across fracture surfaces. App Mech Rev 2013; 64(6):1-20. 
Figure Captions

Figure 1. Composite laminate architecture

Figure 2. In-situ processed double-lap shear panel assembly design

Figure 3. Final panel assembly with release film and spot welded edges

Figure 4. Definition of ply orientations near the lap shear interface

Figure 5. Resistance heated platens with UHMWPE panel

Figure 6. In-house hot press configuration

Figure 7. Process cycle for UHMWPE composite laminates

Figure 8. Illustration of speckle pattern and example of DIC output showing x-direction displacement field

Figure 9. Schematic of boundary conditions with callout showing mesh refinement in the lap shear region

Figure 10. Ramberg-Osgood equation representation for the nonlinear interlaminar shear stressstrain response

Figure 11. Traction-separation law applied at the lap shear interface

Figure 12. Shear cube illustrating the definition of average strain, $\gamma_{a v e}$, measured across the lap shear interface

Figure 13. Average shear stress versus average shear strain response as measured across $10 \%$, $20 \%$ and $30 \%$ of the total coupon thickness

Figure 14. Back calculation of the actual interlaminar shear response based on the average shear stress versus average shear strain as measured across $10 \%$ of the total coupon thickness

Figure 15. Correlation of model predictions with experiments for the average shear stress versus average shear strain response as measured across $10 \%, 20 \%$, and $30 \%$ of the total coupon thickness without traction separation behavior

Figure 16. Predicted shear stress profiles along the lap shear interface for linear and non-linear material property assumptions at coupon loads of $P=250 \mathrm{~N}, P=650 \mathrm{~N}$ and $P=1450 \mathrm{~N}$

Figure 17. Steep displacement and strain gradients near the lap shear interface at $P / A=1300 \mathrm{kPa}$ 
Figure 18. Correlation of model predictions with experiments for the average shear stress versus average shear strain response as measured across $10 \%, 20 \%$, and $30 \%$ of the total coupon thickness with traction separation behavior included

Figure 19. Microscopy of typical lap shear interface failure 
Table 1. Spectra Fiber [24,25], lamina [0] and laminate $[0 / 90 / 0 / 90]_{\mathrm{S}}$ for SR3136 material.

\begin{tabular}{|c|c|c|c|c|c|}
\hline \multicolumn{2}{|c|}{ Fiber Properties } & \multicolumn{2}{|c|}{ Lamina Properties } & \multicolumn{2}{|c|}{ Laminate Properties } \\
\hline$E_{1}^{f}$ & $100 \mathrm{GPa}$ & $E_{1}$ & $85.5 \mathrm{GPa}$ & $E_{x}, E_{y}$ & $45.6 \mathrm{GPa}$ \\
\hline$E_{2}^{f}, E_{3}^{f}$ & $5.00 \mathrm{GPa}$ & $E_{2}, E_{3}$ & $5.06 \mathrm{GPa}$ & $E_{z}$ & 6.07 GPa \\
\hline$G_{12}^{f}, G_{13}^{f}$ & $2.50 \mathrm{GPa}$ & $G_{12}, G_{13}$ & $2.41 \mathrm{GPa}$ & $G_{x z}, G_{y z}$ & $2.41 \mathrm{GPa}$ \\
\hline$G_{23}^{f}$ & $2.50 \mathrm{GPa}$ & $G_{23}$ & $1.75 \mathrm{GPa}$ & $G_{x y}$ & $2.06 \mathrm{GPa}$ \\
\hline$v_{12}^{f}, v_{13}^{f}$ & 0.30 & $v_{12}, v_{13}$ & 0.30 & $v_{x z}, v_{y z}$ & 0.03 \\
\hline$v_{23}^{f}$ & 0.45 & $v_{23}$ & 0.44 & $v_{x y}$ & 0.06 \\
\hline
\end{tabular}




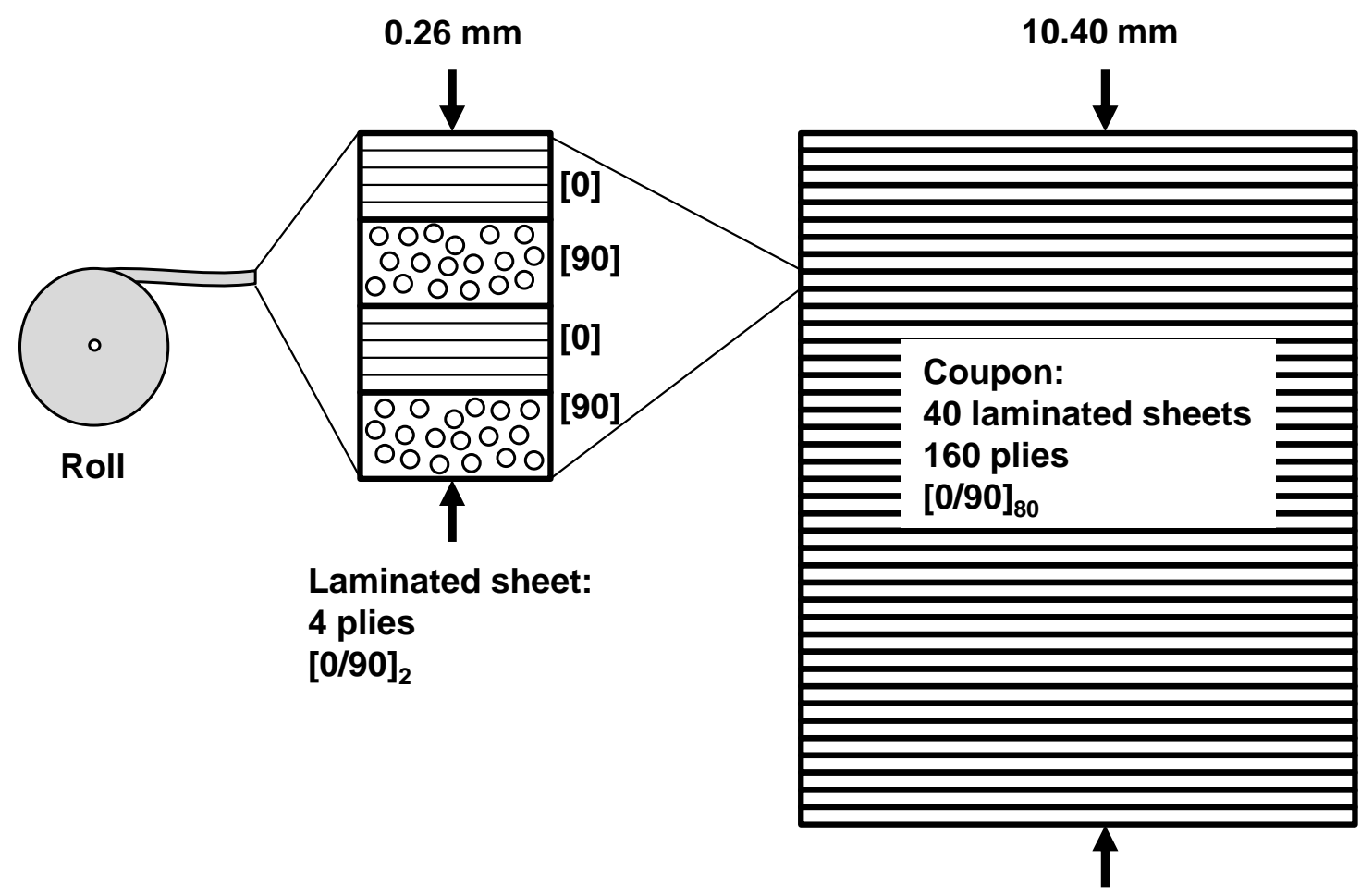

Figure 1. Composite laminate architecture
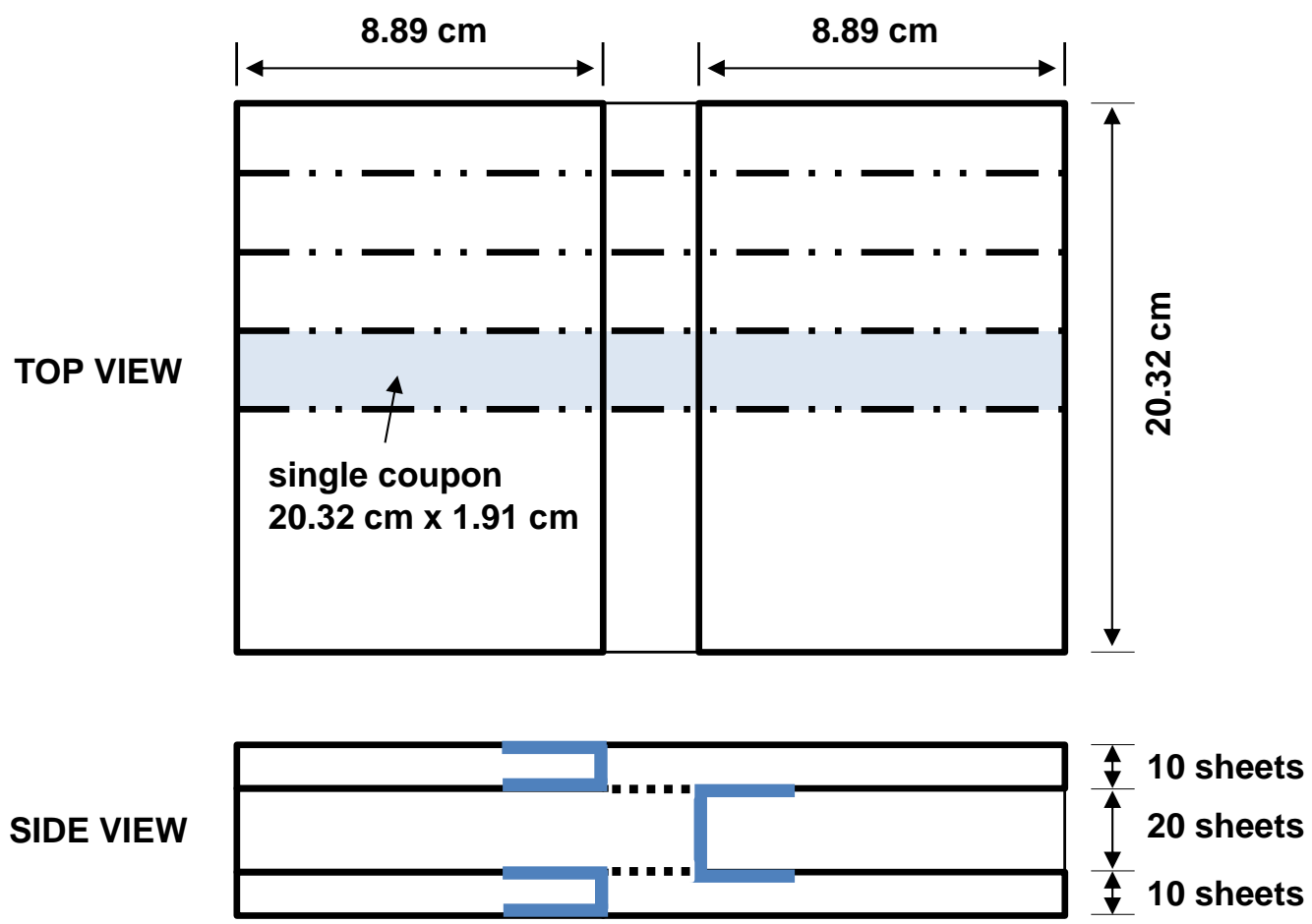

release film

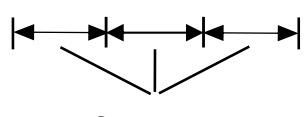

$2.54 \mathrm{~cm}$

Figure 2. In-situ processed double-lap shear panel assembly design 


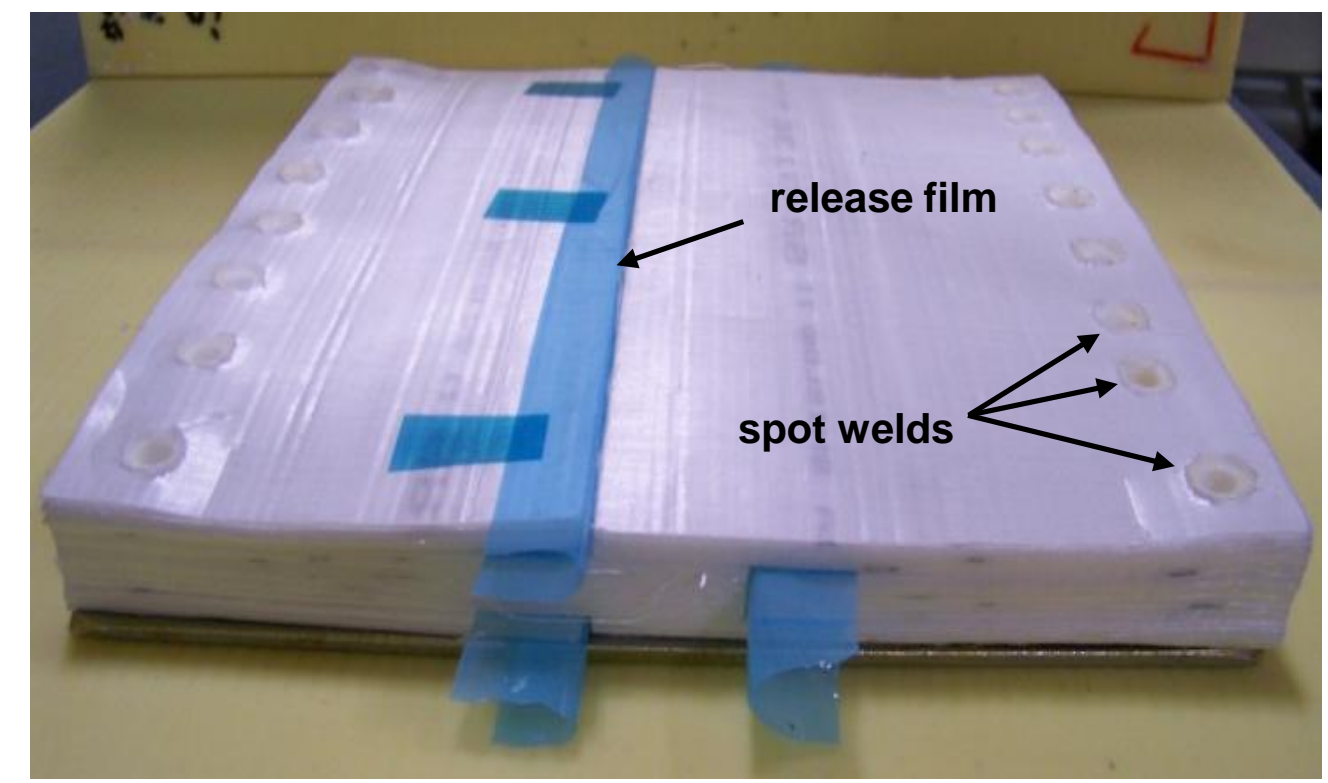

Figure 3. Final panel assembly with release film and spot welded edges

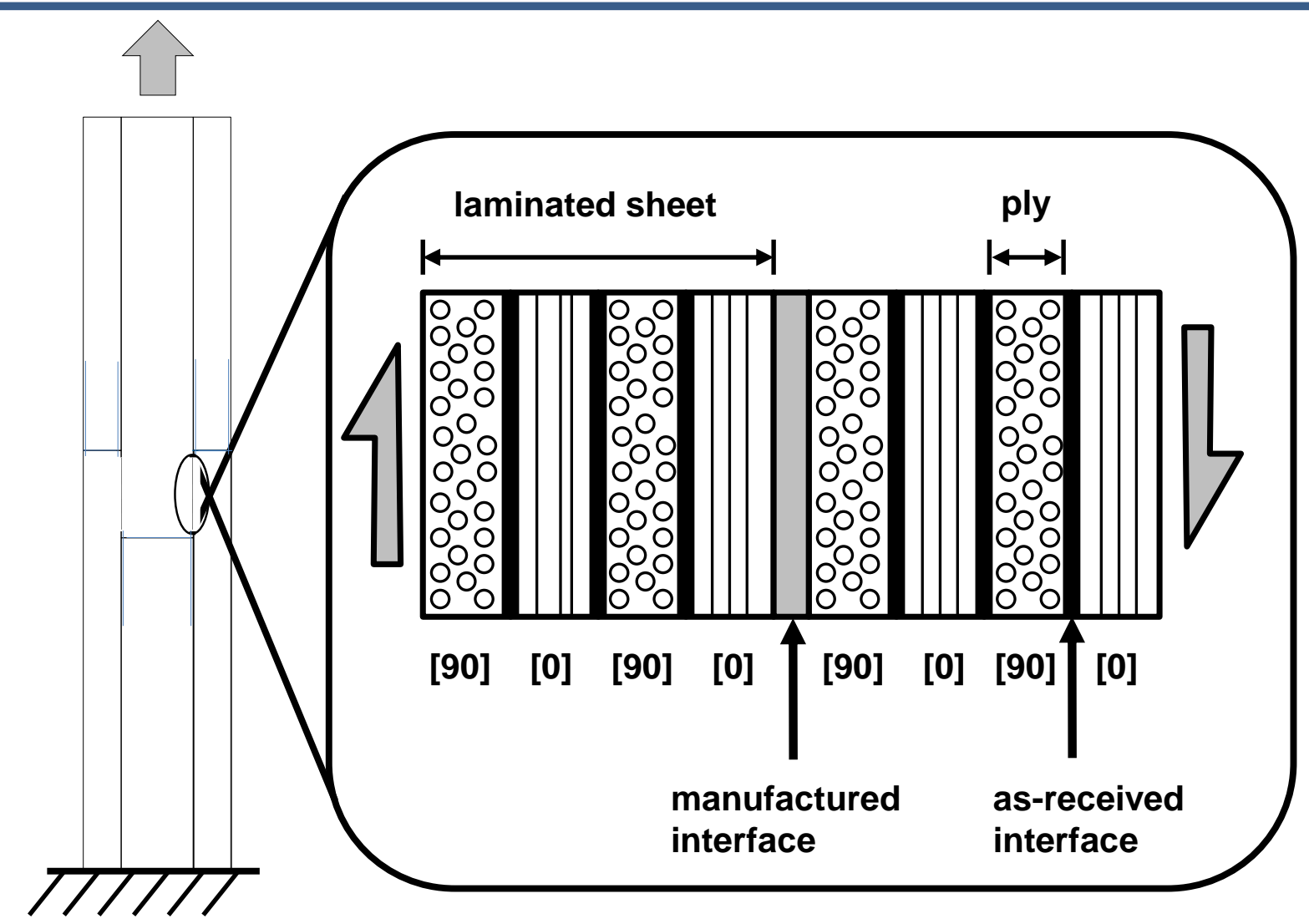

Figure 4. Definition of ply orientations near the lap shear interface 


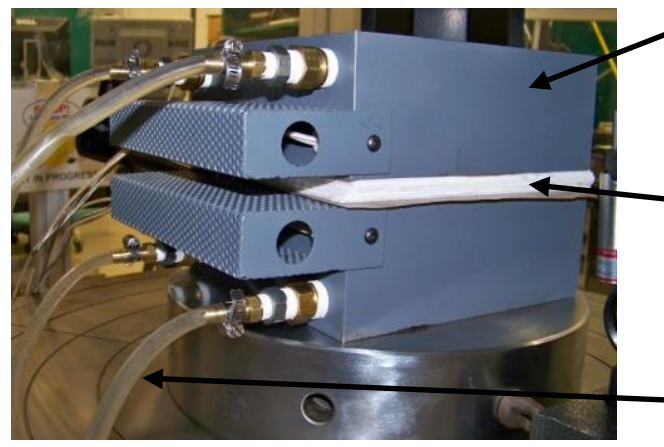

resistance heated steel platen

UHMWPE composite panel

cooling lines

Figure 5. Resistance heated platens with UHMWPE panel

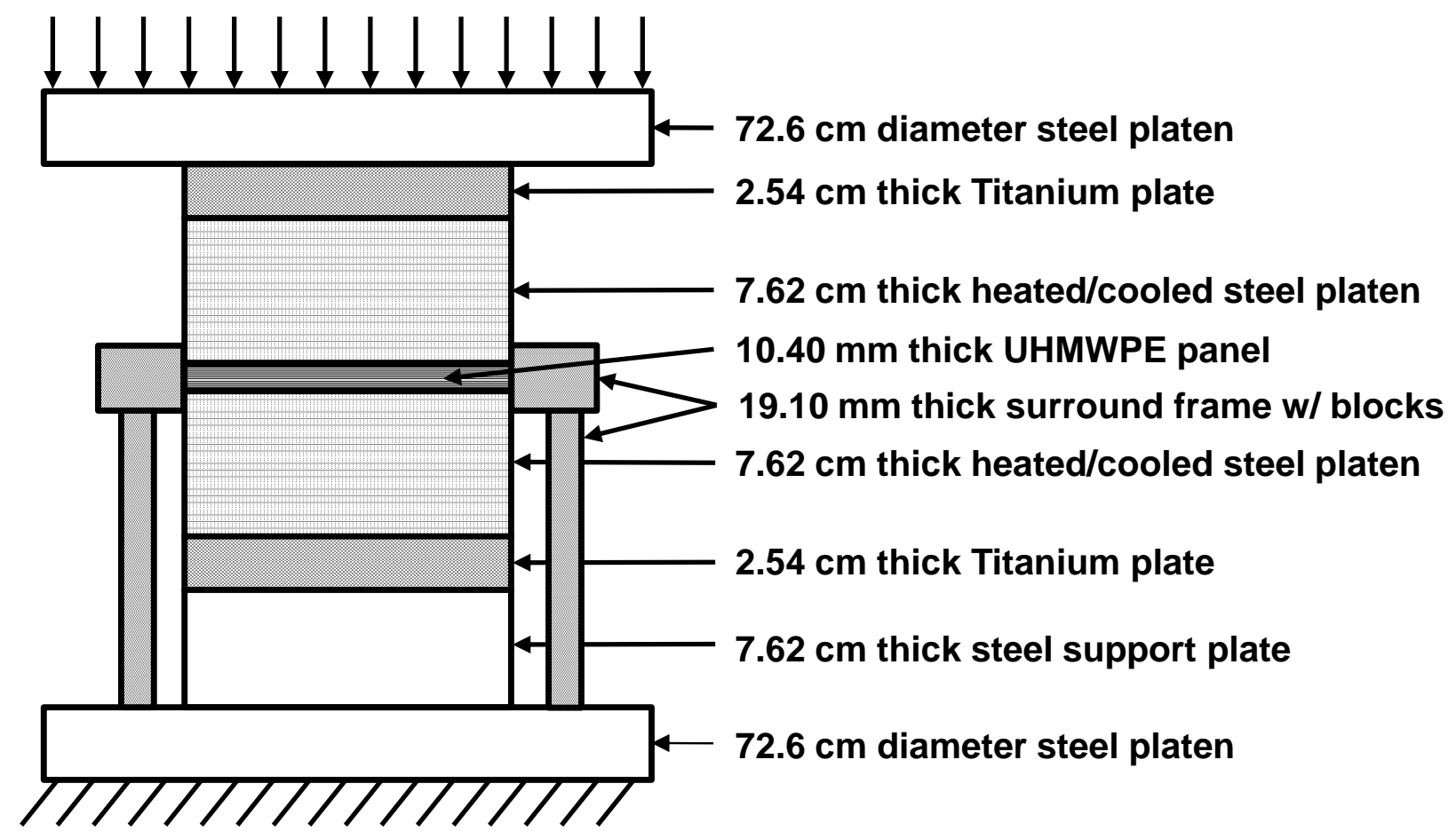

Figure 6. In-house hot press configuration 


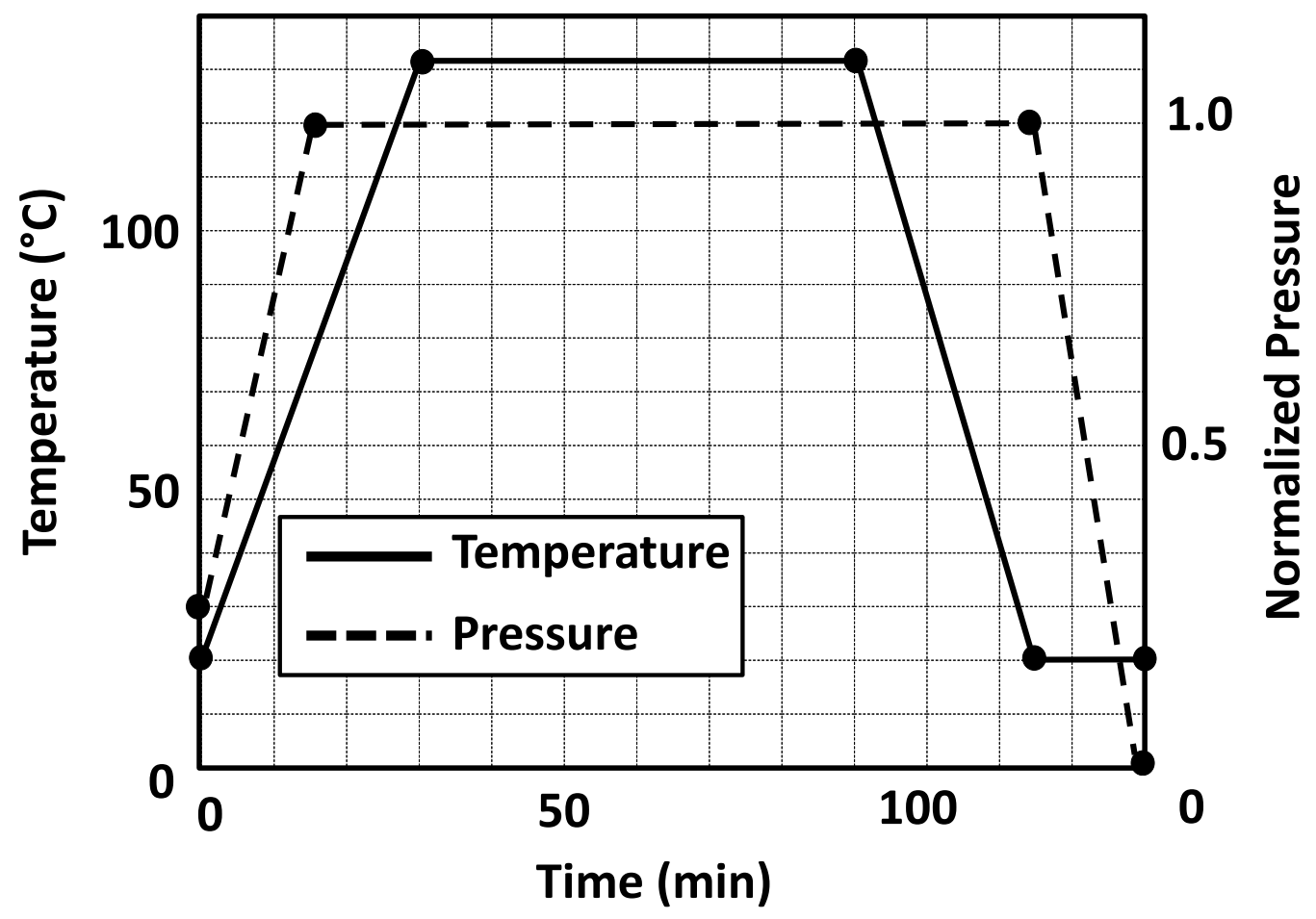

Figure 7. Process cycle for UHMWPE composite laminates

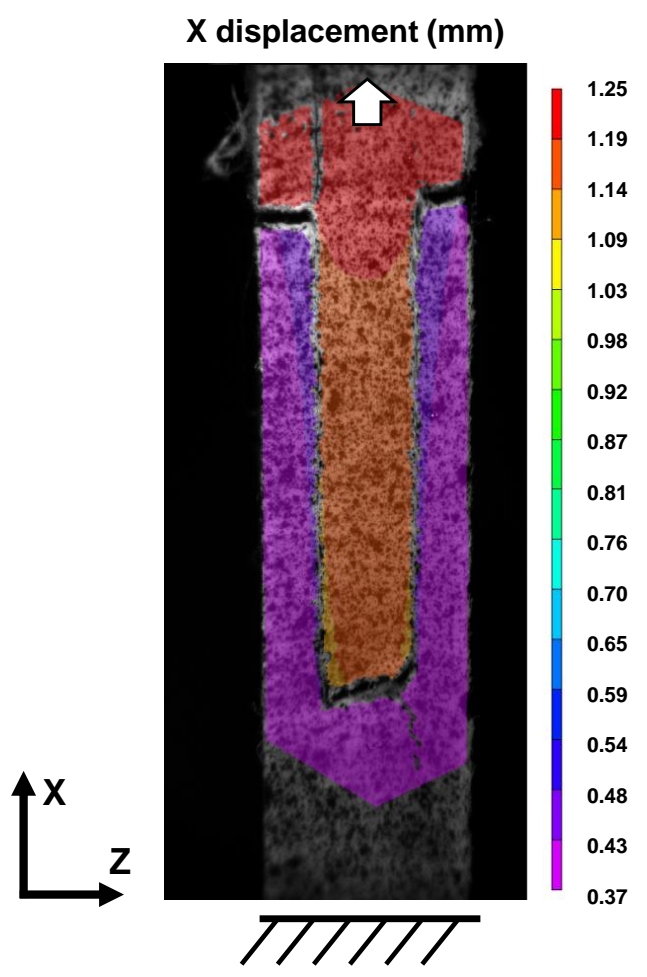

Figure 8. Illustration of speckle pattern and example of DIC output showing $x$-direction displacement field 
fixed displacements

displacement controlled loading

$\delta \mathrm{x}=0$

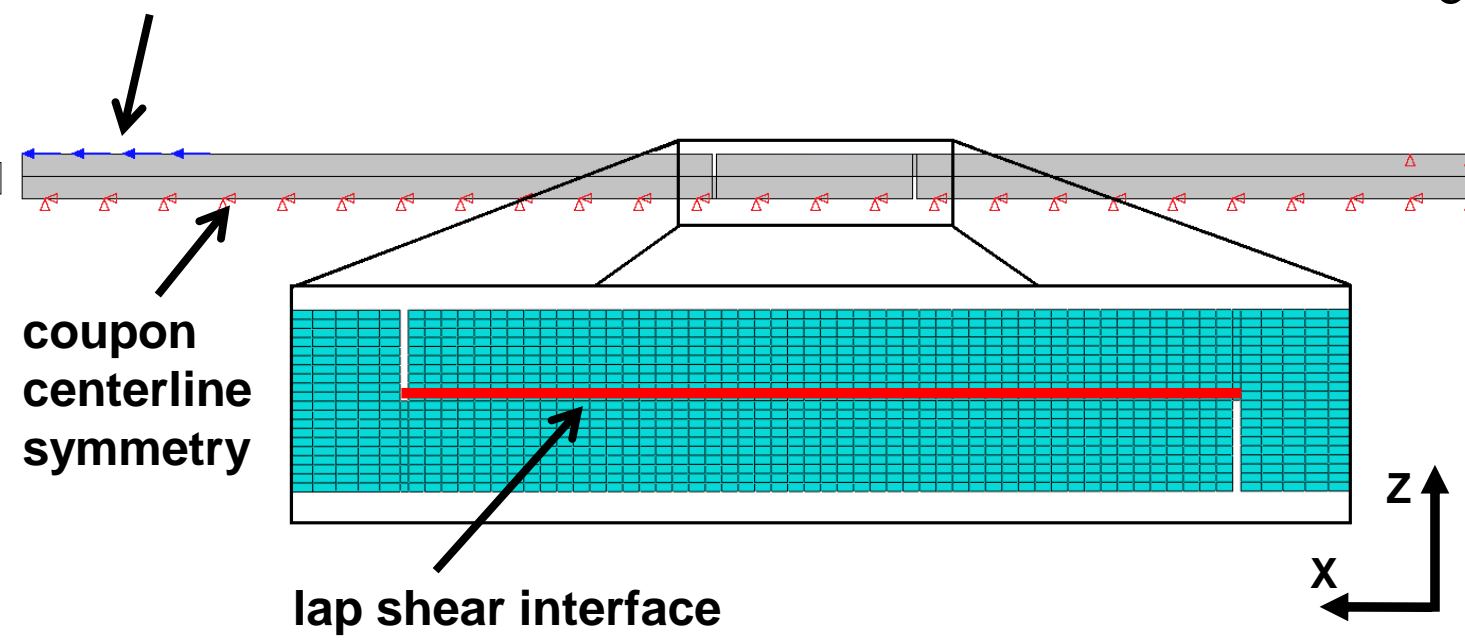

Figure 9. Schematic of boundary conditions with callout showing mesh refinement in the lap shear region

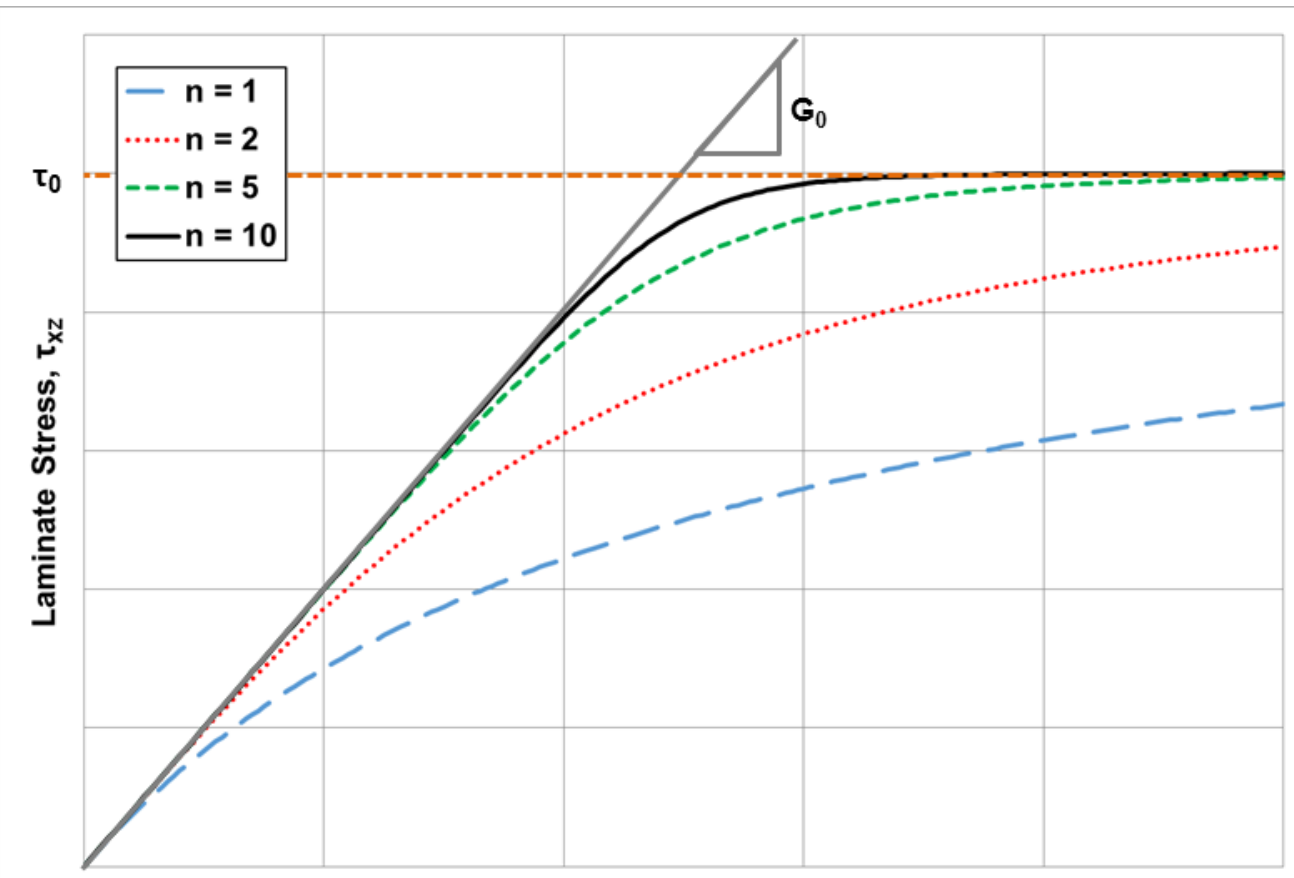

Laminate Strain, $\gamma_{x z}$

Figure 10. Ramberg-Osgood equation representation for the nonlinear interlaminar shear stress-strain response 


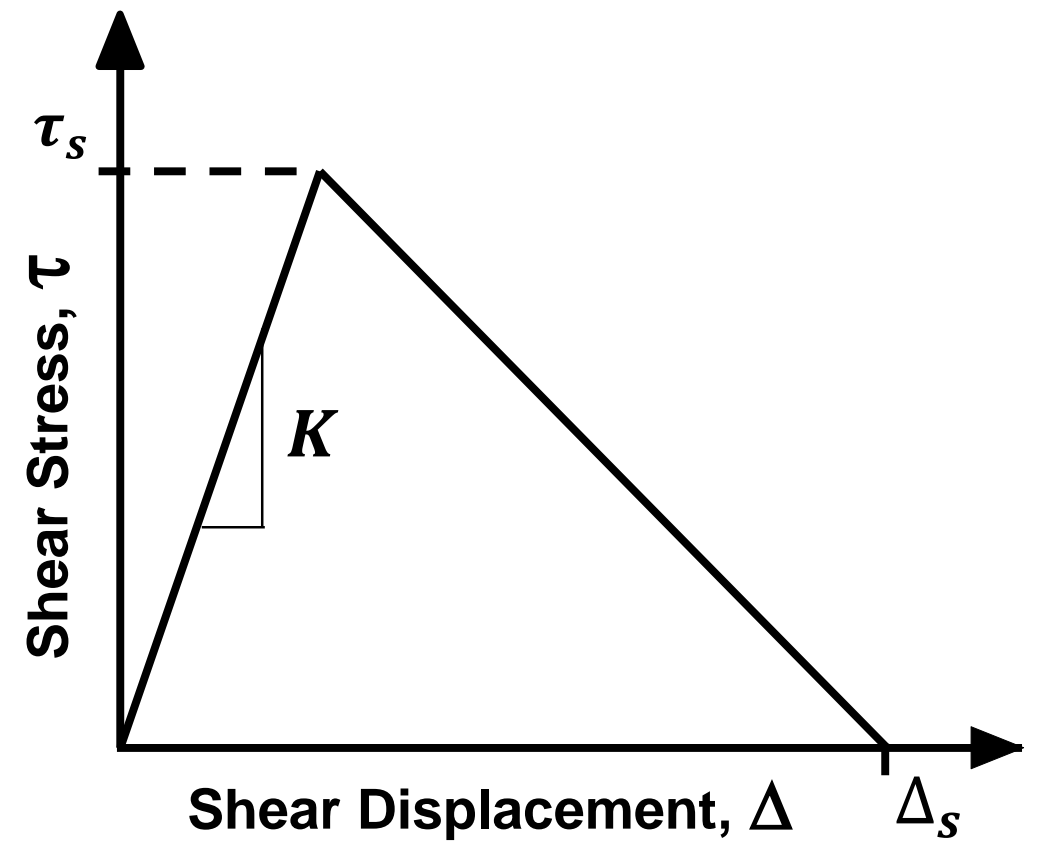

Figure 11. Traction-separation law applied at the lap shear interface

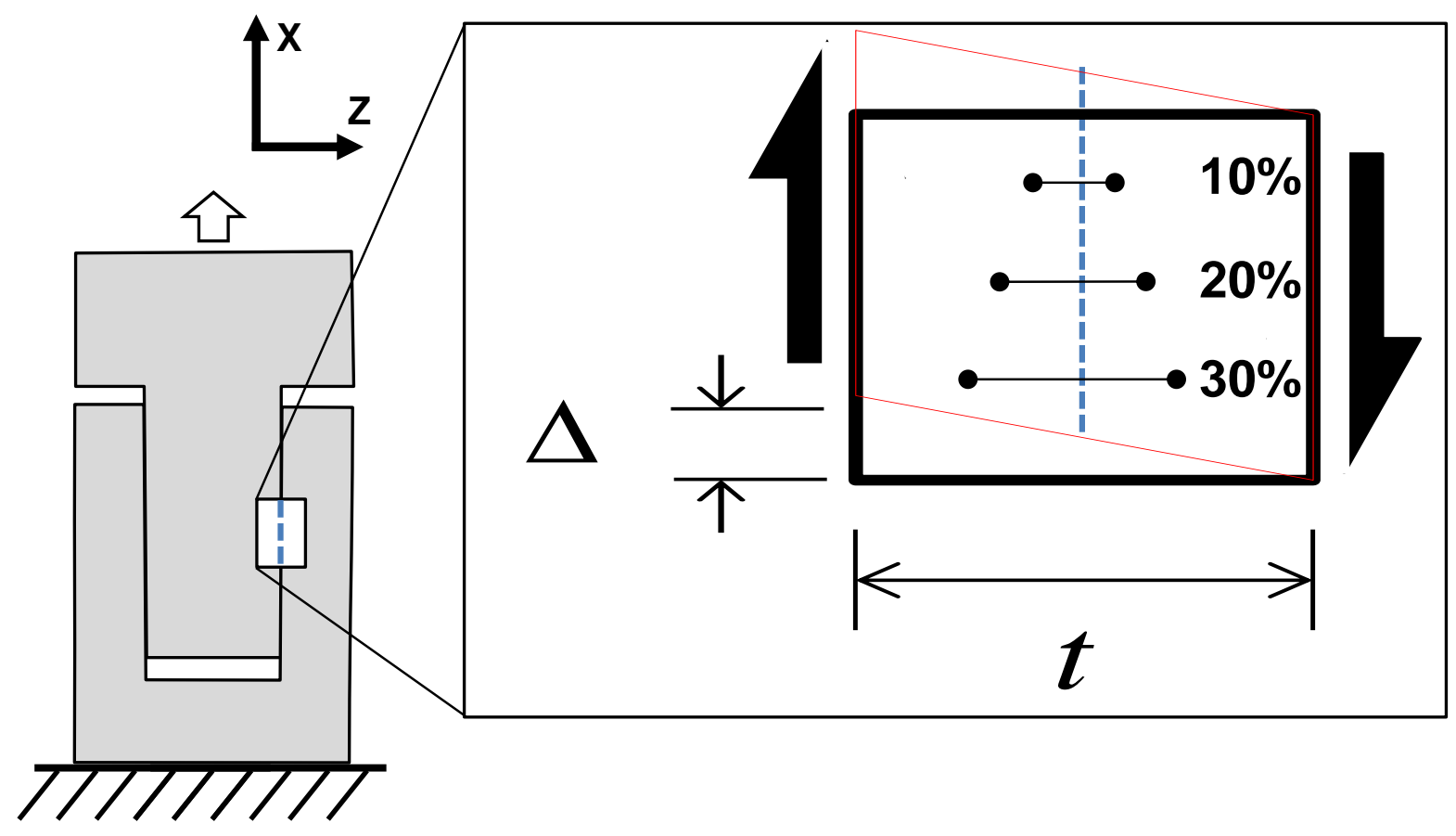

Figure 12. Shear cube illustrating the definition of average strain, $\gamma_{\text {ave }}$, measured across the lap shear interface 


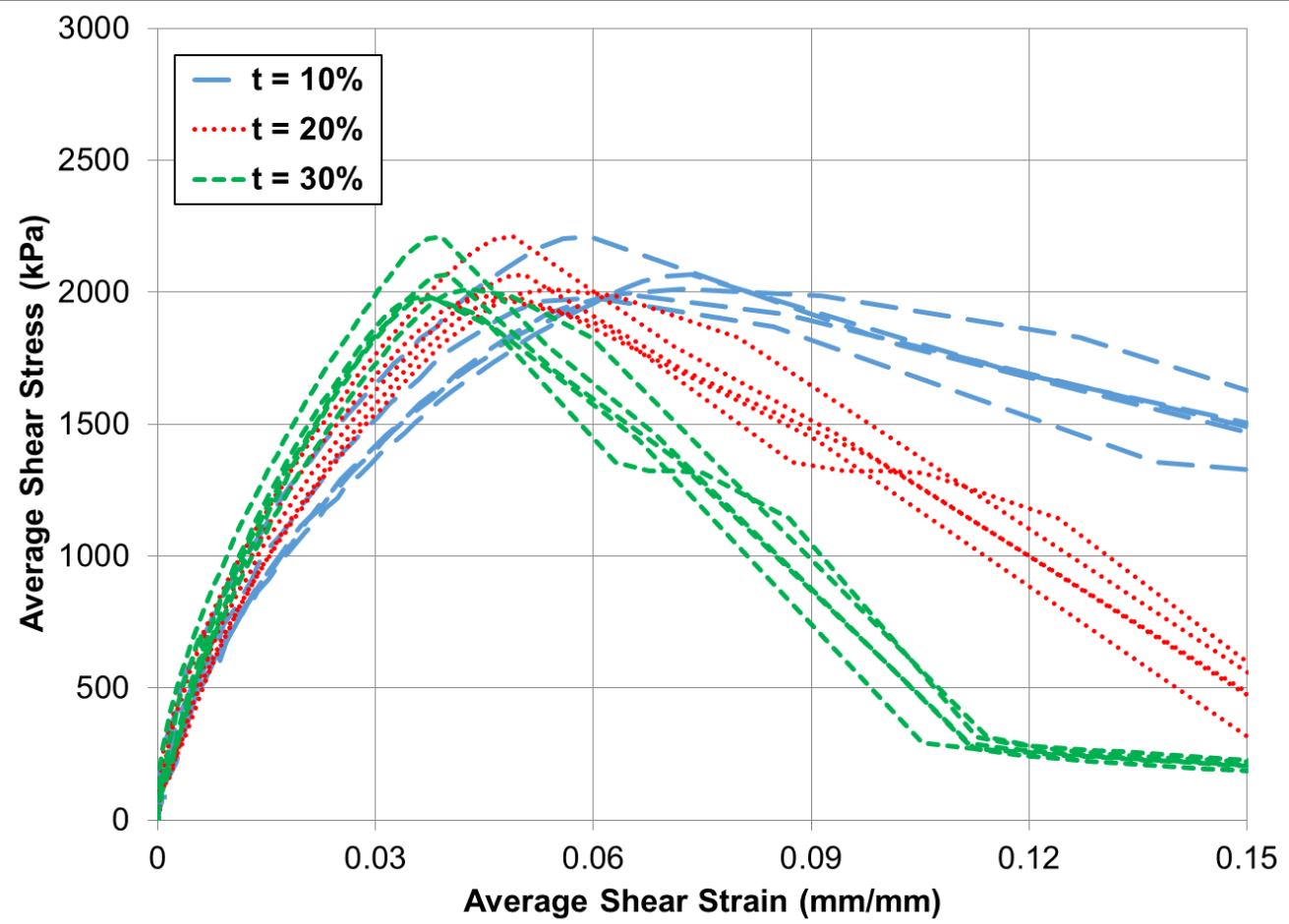

Figure 13. Average shear stress versus average shear strain response as measured across $10 \%, 20 \%$, and $30 \%$ of the total coupon thickness

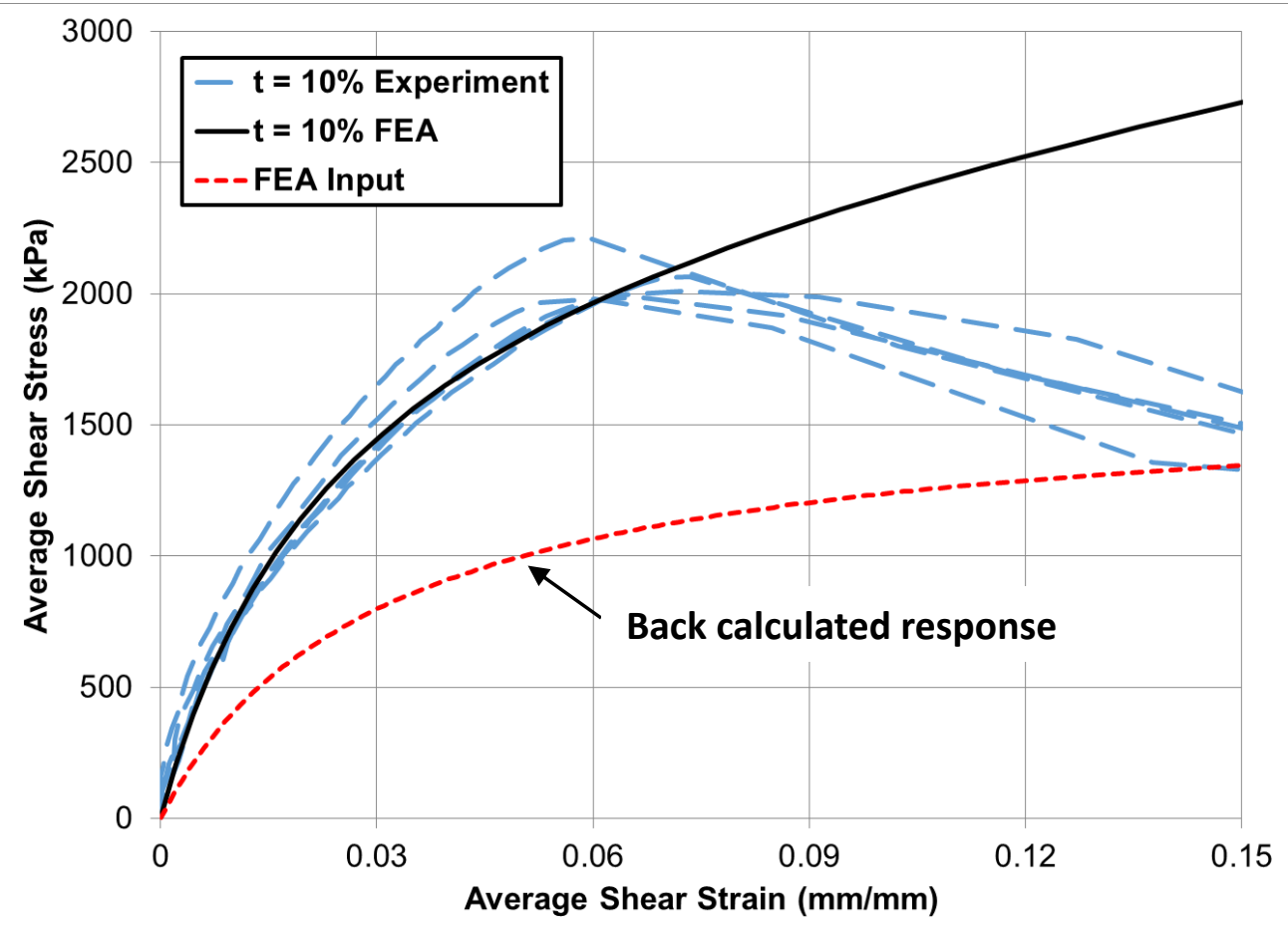

Figure 14. Back calculation of the actual interlaminar shear response based on the average shear stress versus average shear strain as measured across $10 \%$ of the total coupon thickness 


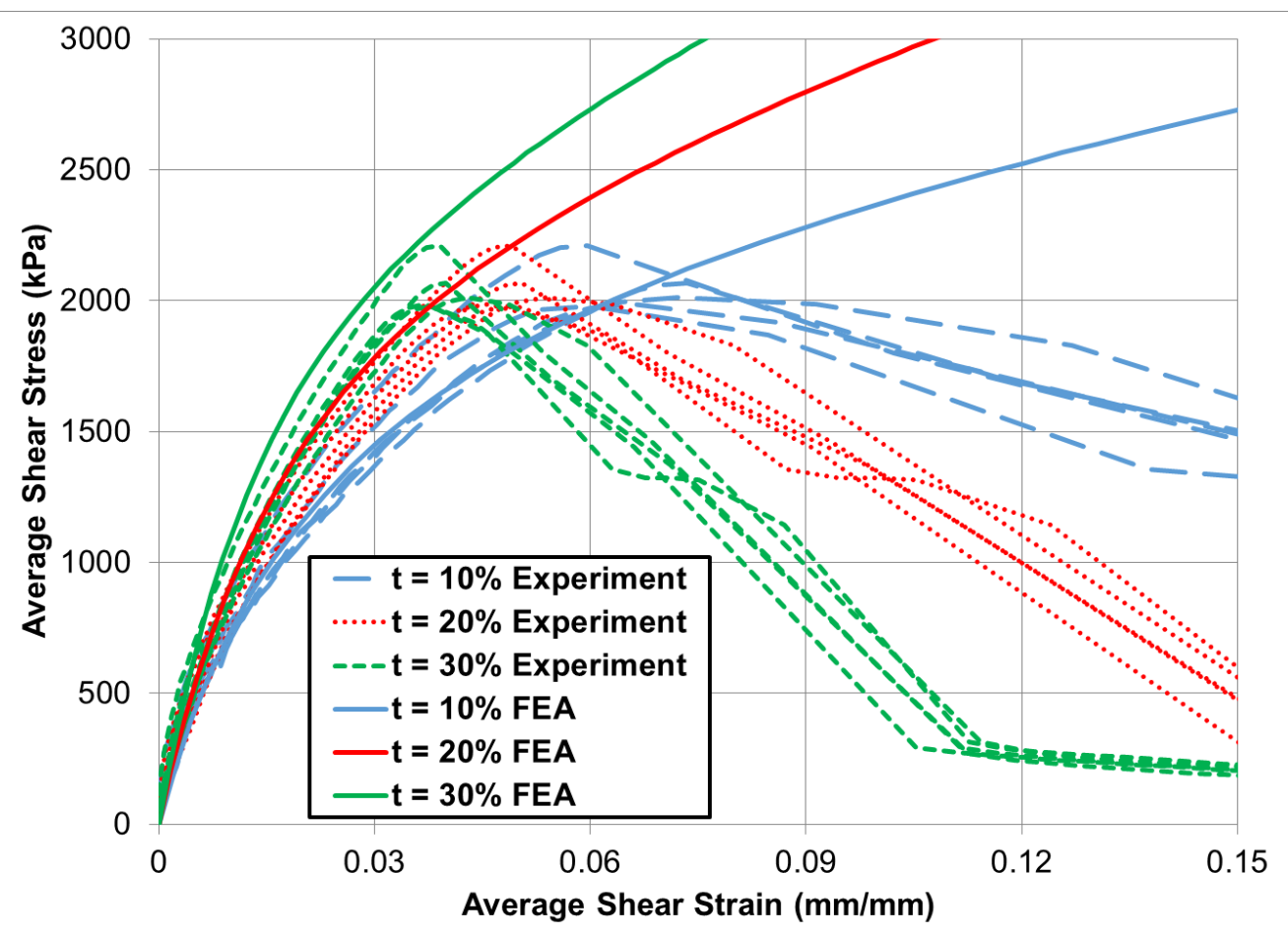

Figure 15. Correlation of model predictions with experiments for the average shear stress versus average shear strain response as measured across $10 \%, 20 \%$, and $30 \%$ of the total coupon thickness without traction separation behavior

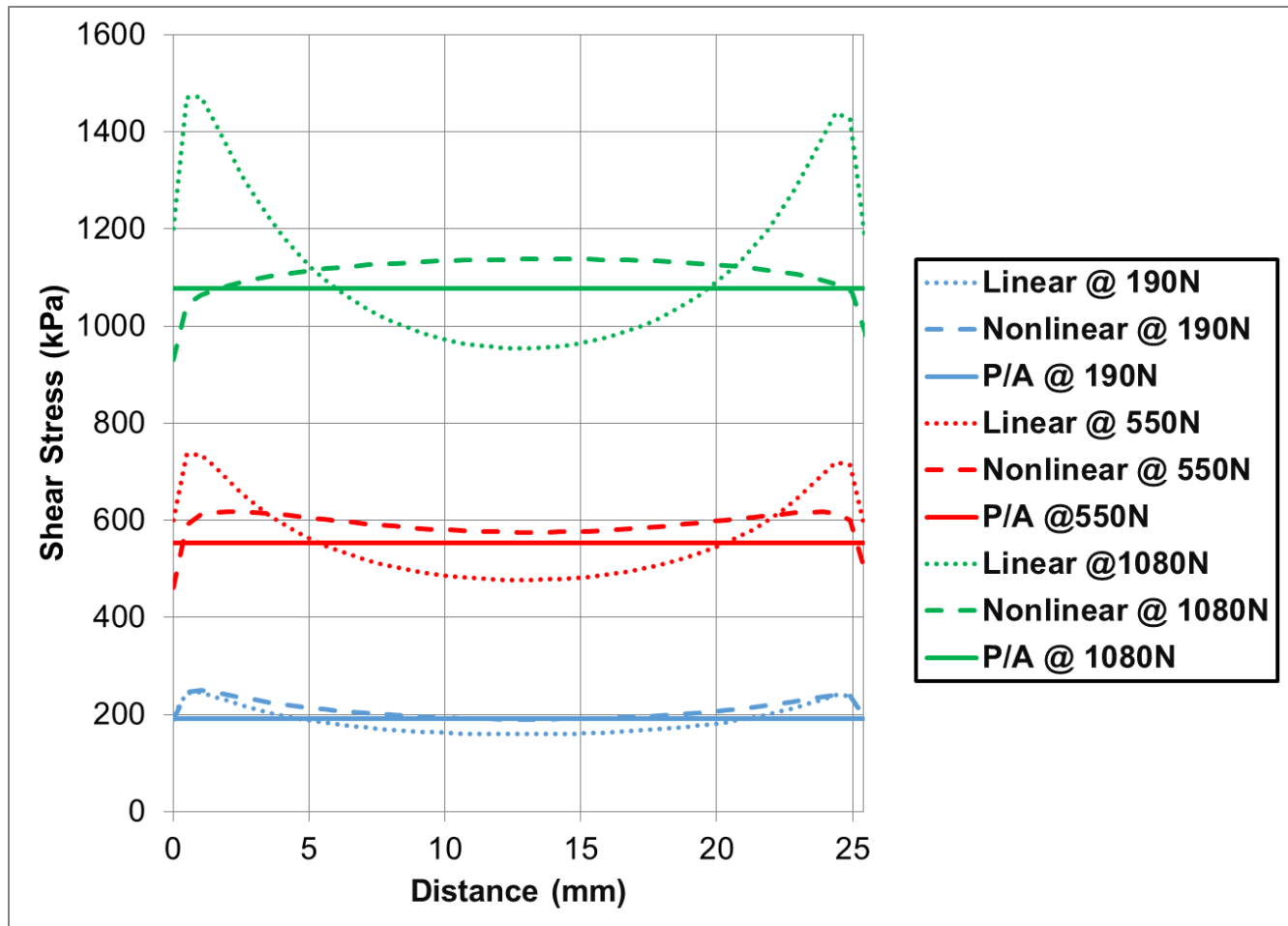

Figure 16. Predicted shear stress profiles along the lap shear interface for linear and non-linear material property assumptions at coupon loads of $P=190 \mathrm{~N}, P=550 \mathrm{~N}$ and $P=1080 \mathrm{~N}$ 


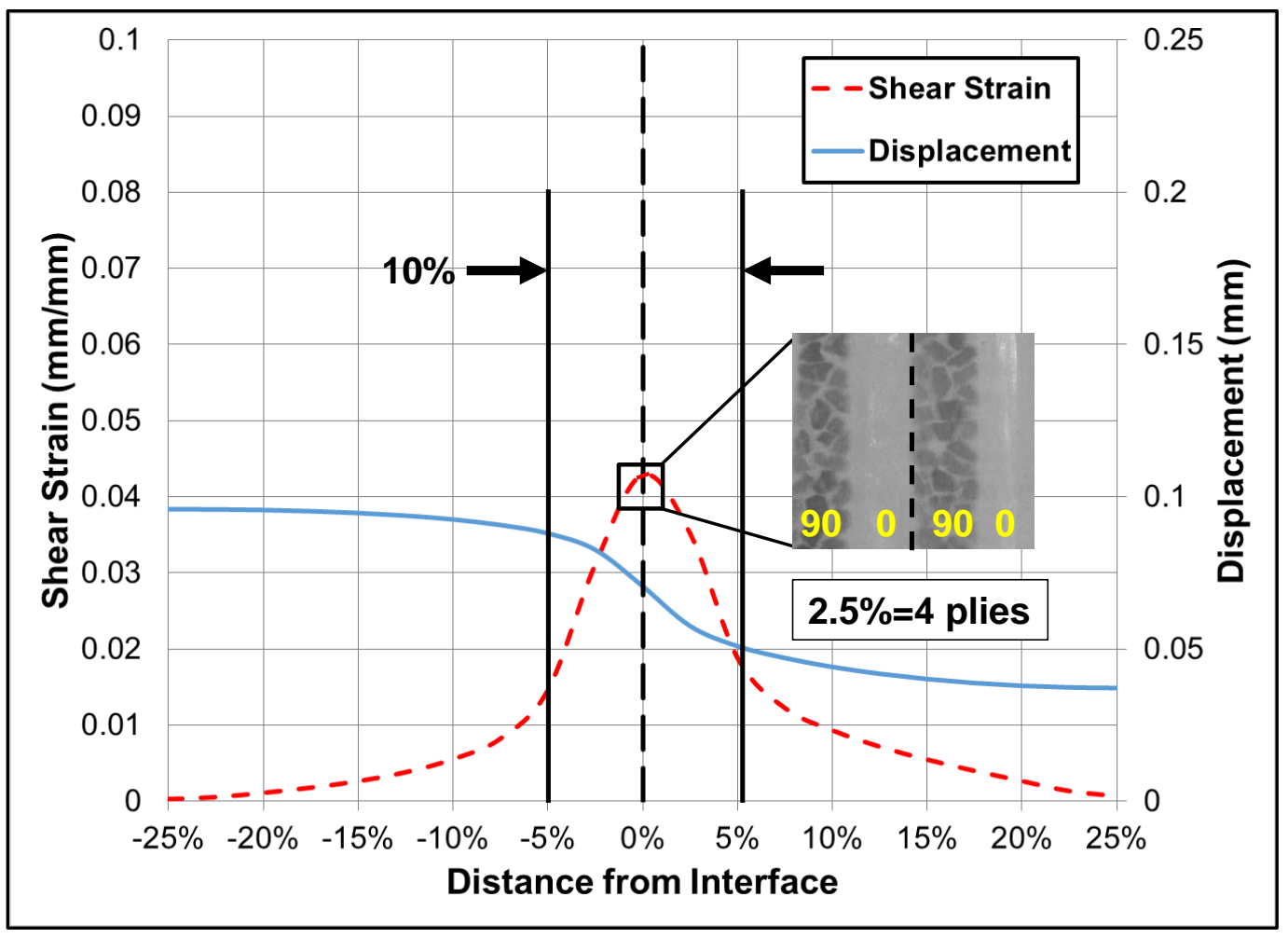

Figure 17. Steep displacement and strain gradients near the lap shear interface at $P / A=1300 \mathrm{kPa}$

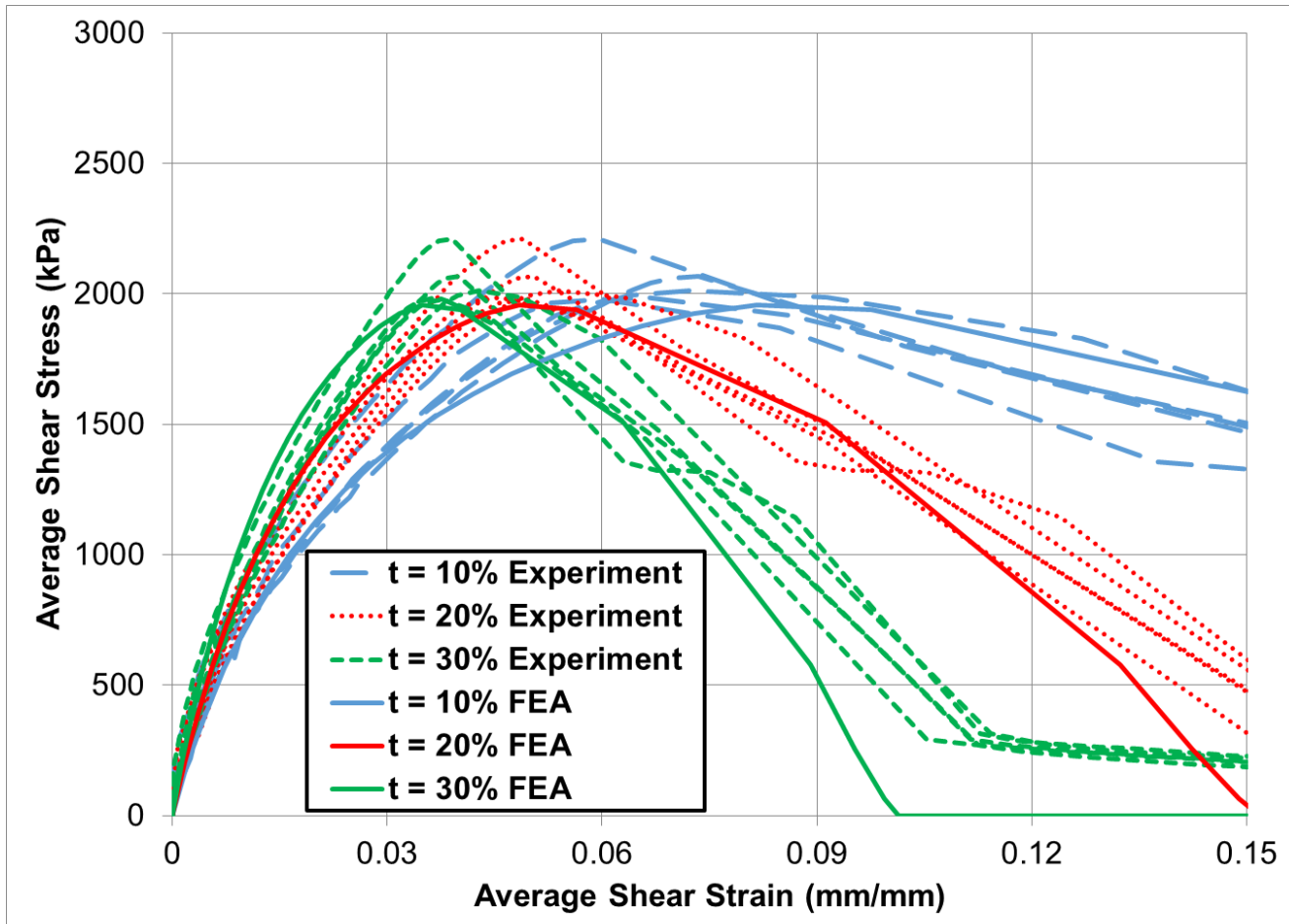

Figure 18. Correlation of model predictions with experiments for the average shear stress versus average shear strain response as measured across $10 \%$, $20 \%$, and $30 \%$ of the total coupon thickness with traction separation behavior included 

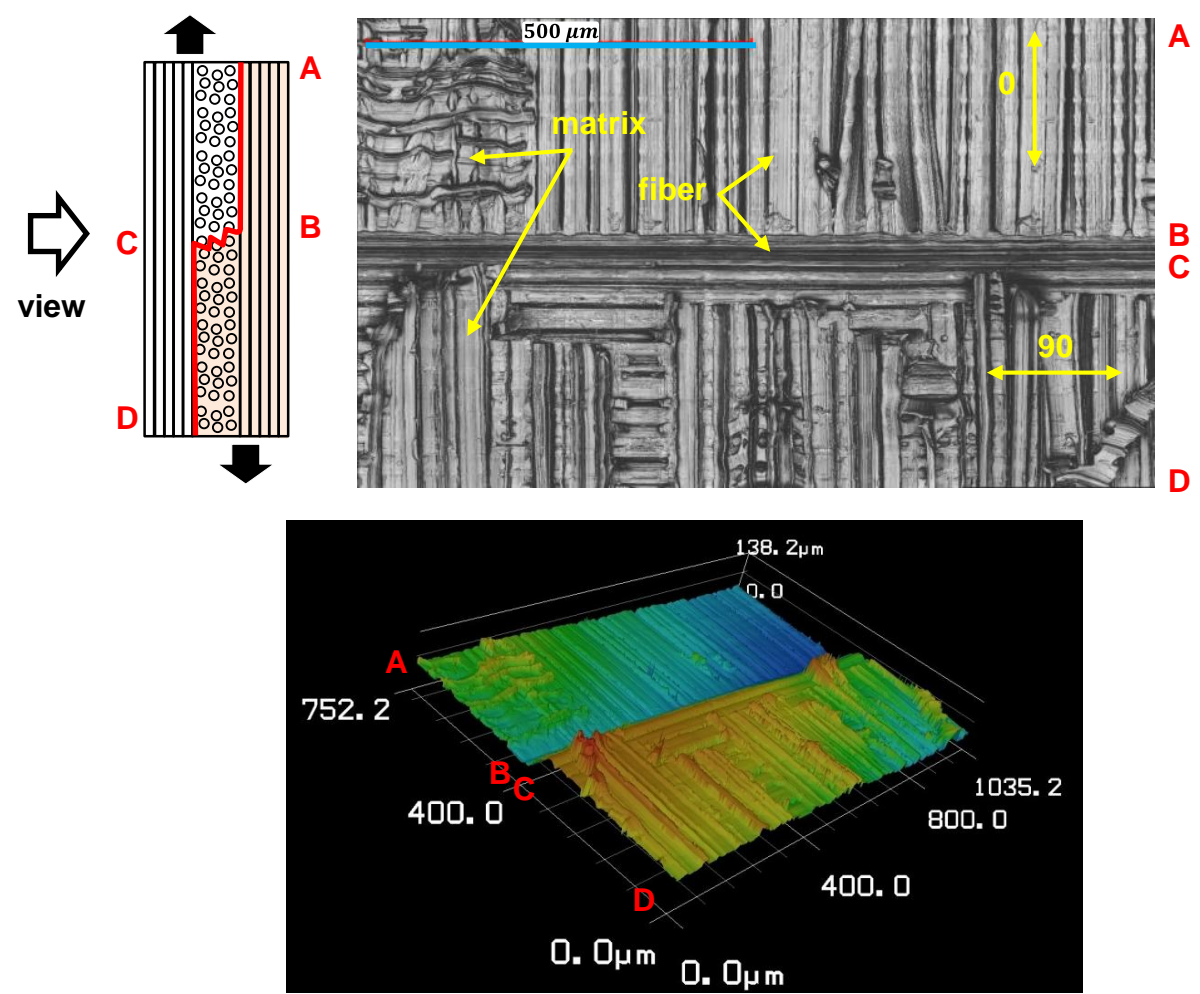

Figure 19. Microscopy of typical lap shear interface failure 